\title{
Modelling pyroclastic density currents from a subplinian eruption at La Soufrière de Guadeloupe (West Indies, France)
}

\author{
Tomaso Esposti Ongaro $^{1}$ (D) $\cdot$ Jean-Christophe Komorowski ${ }^{2} \cdot$ Yoann Legendre $^{3} \cdot$ Augusto Neri $^{1}$
}

Received: 29 February 2020 / Accepted: 1 October 2020 / Published online: 13 November 2020

(C) The Author(s) 2020

\begin{abstract}
We have used a three-dimensional, non-equilibrium multiphase flow numerical model to simulate subplinian eruption scenarios at La Soufrière de Guadeloupe (Lesser Antilles, France). Initial and boundary conditions for computer simulations were set on the basis of independent estimates of eruption source parameters (i.e. mass eruption rate, volatile content, temperature, grain size distribution) from a field reconstruction of the $1530 \mathrm{CE}$ subplinian eruption. This event is here taken as a reference scenario for hazard assessment at La Soufrière de Guadeloupe. A parametric study on eruption source parameters allowed us to quantify their influence on the simulated dynamics and, in particular, the increase of the percentage of column collapse and pyroclastic density current (PDC) intensity, at constant mass eruption rate, with variable vent diameter. Numerical results enabled us to quantify the effects of the proximal morphology on distributing the collapsing mass around the volcano and into deep and long valleys and to estimate the areas invaded by PDCs, their associated temperature and dynamic pressure. Significant impact (temperature $>300^{\circ} \mathrm{C}$ and dynamic pressure $>1 \mathrm{kPa}$ ) in the inhabited region around the volcano is expected for fully collapsing conditions and mass eruption rates $>2 \times 10^{7} \mathrm{~kg} / \mathrm{s}$. We thus combine this spatial distribution of temperature and dynamic pressure with an objective consideration of model-related uncertainty to produce preliminary PDC hazard maps for the reference scenario. In such a representation, we identify three areas of varying degree of susceptibility to invasion by PDCs - very likely to be invaded (and highly impacted), susceptible to invasion (and moderately impacted), and unlikely to be invaded (or marginally impacted). The study also raises some key questions about the use of deterministic scenario simulations for hazard assessment, where probability distributions and uncertainties are difficult to estimate. Use of high-performance computing techniques will in part allow us to overcome such difficulties, but the problem remains open in a scientific context where validation of numerical models is still, necessarily, an incomplete and ongoing process. Nevertheless, our findings provide an important contribution to the quantitative assessment of volcanic hazard and risk at La Soufrière de Guadeloupe particularly in the context of the current unrest of the volcano and the need to prepare for a possible future reawakening of the volcano that could culminate in a magmatic explosive eruption.
\end{abstract}

Keywords La Soufrière de Guadeloupe $\cdot$ Pyroclastic density currents $\cdot$ Subplinian eruption $\cdot$ Numerical simulation $\cdot$ Hazard assessment

\section{Introduction}

Editorial responsibility: C.E.Gregg

Tomaso Esposti Ongaro

tomaso.espostiongaro@ingv.it

1 Istituto Nazionale di Geofisica e Vulcanologia (INGV), Sezione di Pisa, Italy

2 Université de Paris, Institut de Physique du Globe de Paris (IPGP), CNRS, Paris, France

3 Bureau de Recherches Géologiques et Minières (BRGM), Petit-Bourg, Guadeloupe, France
Pyroclastic density currents are rapidly moving, gravitydriven flows of gas and hot volcanic particles (ash, lapilli, and blocks) produced during explosive eruptions (Sparks et al. 1978; Druitt 1998; Branney and Kokelaar 2002). They represent extreme hazards at active volcanoes by virtue of their rapid propagation, attaining velocities of up to $60 \mathrm{~m} / \mathrm{s}$ (e.g. Yamamoto et al. 1993; Loughlin et al. 2002; Komorowski et al. 2015), destructive potential (Spence et al. 2004; Baxter et al. 2005; Jenkins et al. 2010, 2013a), and for the lethal conditions rapidly establishing in the inundated areas (Baxter et al. 2017). Assessing PDC hazards and their 
associated uncertainty is a challenging task, mostly because of the diversity of PDC generation mechanisms, producing currents with diverse compositions and in a wide range of flow regimes (Fujii and Nakada 1999; Branney and Kokelaar 2002) and by reason of their complex interaction with an incised volcano topography, often leading to unpredictable flow transformations (Fisher 1995; Druitt et al. 2002b; Ogburn et al. 2014; Komorowski et al. 2015). One way to assess hazard and risk at vulnerable sites is through model-based appraisals of PDC invasion and maximum runout, and mapping of hazardous actions in the inundated areas (cf. Calder et al. 2015; Takarada 2017; Lube et al. 2020). Such hazard mapping has been developed both for quiescent volcanoes (e.g. Esposti Ongaro et al. 2008a; Brand et al. 2014; Neri et al. 2015a) and to manage eruptive crises (Wadge and Aspinall 2014; Neri et al. 2015b). Here, we apply a modelling approach to PDC hazard assessment for a subplinian eruption scenario at La Soufrière de Guadeloupe volcano.
The Grande Découverte - Soufrière de Guadeloupe volcanic complex is located on the island of Basse-Terre, in the French Lesser Antilles (Fig. 1). It comprises three stratovolcanoes: Grande Découverte, Carmichael, and La Soufrière de Guadeloupe (SDG) (Fig. 2), which were built during the last 445,000 years (Carlut et al. 2000; Samper et al. 2009). La Soufrière de Guadeloupe is an andesitic composite volcano whose activity over the last 10,000 years has been characterized by a diversity of eruptive styles, including effusive and domeforming eruptions, explosive phreatic or hydrothermal and magmatic (Vulcanian to plinian) eruptions, and numerous flank collapse events (Komorowski et al. 2002, 2005; Boudon et al. 2007; Legendre 2012). The most recent magmatic subplinian eruption dates from $1530 \mathrm{CE}$ (Boudon et al. 2008; Komorowski et al. 2008), and a smaller magmatic (Vulcanian to subplinian) eruption took place in $1657 \mathrm{CE}$ (Legendre 2012; Rosas-Carbajal et al. 2016). The historical activity since the 1657 eruption has been characterized by minor (1690, 1812, and 1956) and major
Fig. 1 The Lesser Antilles arc. Bathymetry is from Smith and Sandwell (1997). Contour interval is $500 \mathrm{~m}$. Volcanic islands are black, and subaerial coral reef platforms are dark grey. The 100$\mathrm{m}$ depth submarine shelf is light grey (Modified Boudon et al. 2008)

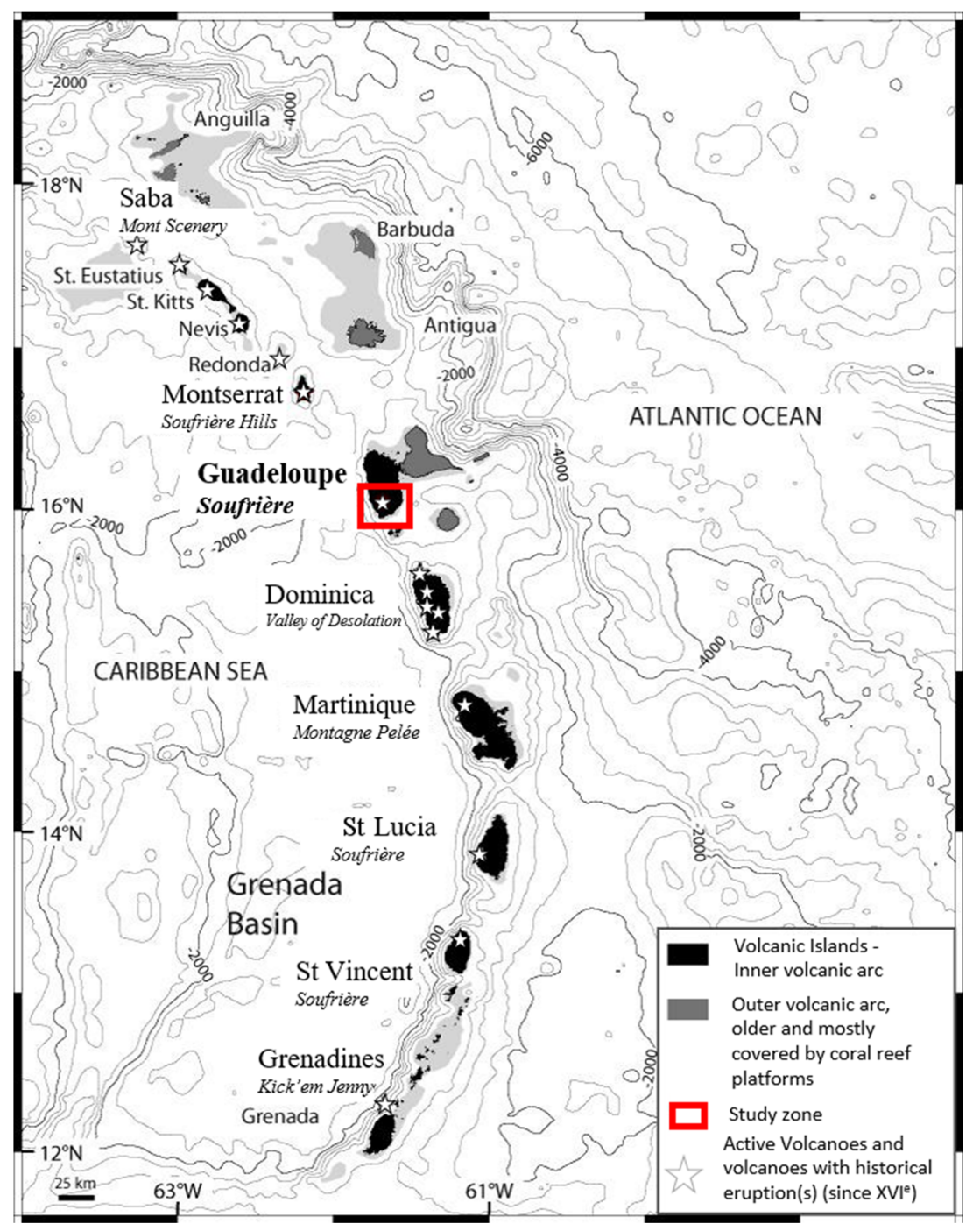



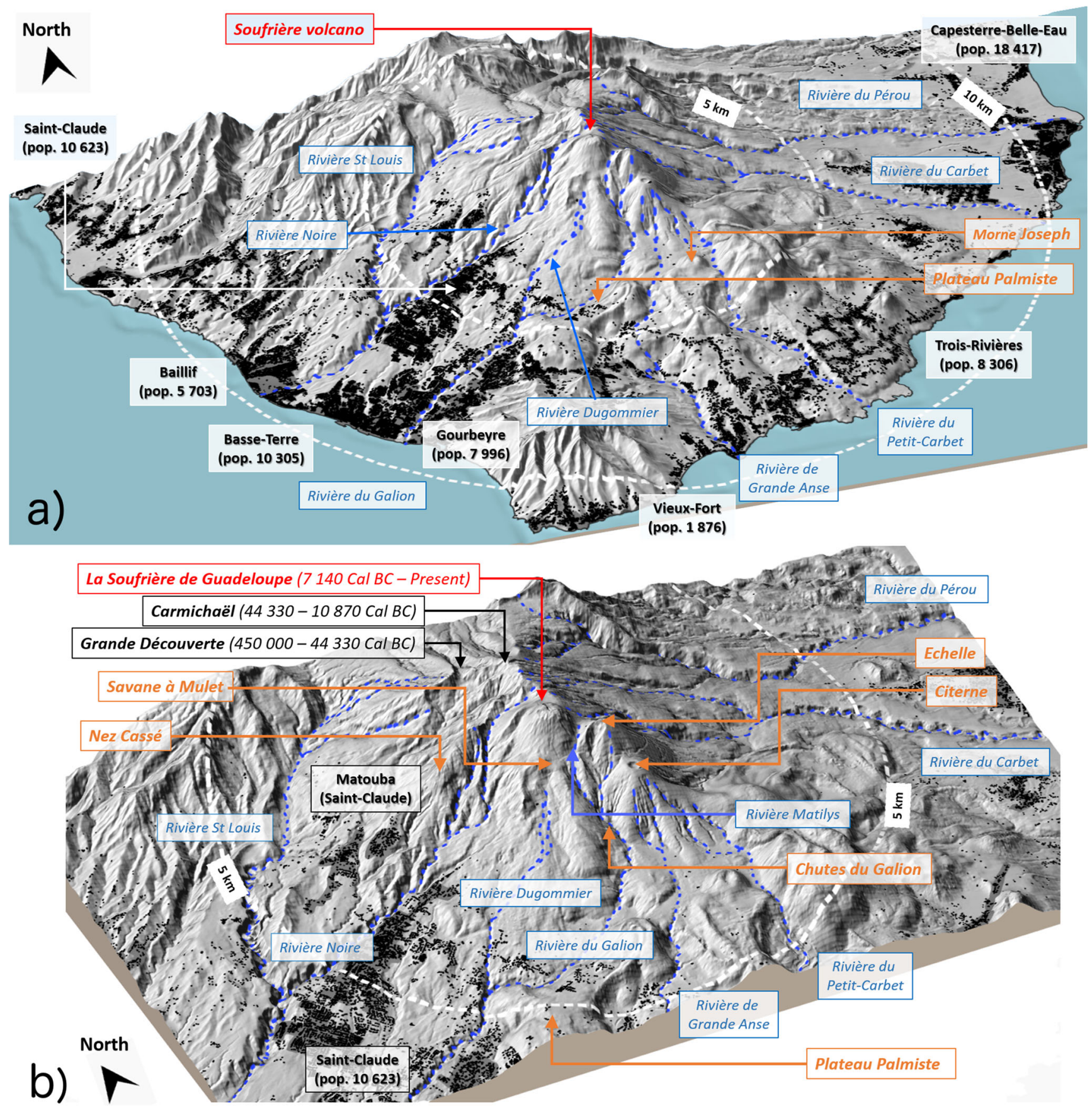

Fig. 2 Main topographic elements and locations mentioned in the paper: a) Southern Basse-Terre area (study zone; cf. Fig. 1); b) zoom on the SDG most proximal area. Demographic data are taken from INSEE (French National Institute of Statistics and Economic Studies) reference data

(1797-1798, 1836-1837, and 1976-1977) non-magmatic (phreatic) eruptions. These eruptions have taken place from fractures and vents on SDG's lava dome (Feuillard et al. 1983; Boudon et al. 1988; Komorowski et al. 2005; Rosas-Carbajal et al. 2016). The last and most violent phreatic eruption occurred in 1976-1977 and forced the evacuation of about 73,600 people for up to 4 months. Although it did not evolve into a magmatic eruption, geophysical and geochemical evidence supported its
(January 1, 2020). Vertical exaggeration of the topography is by a factor of 1.5. The digital elevation model and building data are from BDAlti® and BDTopo® databases, IGN (Institut Géographique National, France)

interpretation as a shallow intrusion that did not feed an eruption (Feuillard et al. 1983; Villemant et al. 2005). This failed magmatic eruption (Moran et al. 2011) involved a small-volume magma intrusion that ascended from the 6-8.5-km-deep magma reservoir (Pichavant et al. 2018) and stagnated at shallower depth, pressurizing the hydrothermal system at a depth of about $500 \mathrm{~m}$ below the summit (Feuillard et al. 1983; Boudon et al. 1988; Villemant et al. 2005; Hincks et al. 2014). 
Although interpretation of the eruptive history of SDG has been particularly difficult on account of erosion and alteration processes that are particularly intense under the tropical climate, geological studies suggest there have been several magmatic explosive eruptions in the last 10,000 years including at least two subplinian VEI 2-3 and six Plinian VEI 4 (Komorowski et al. 2005; Legendre 2012). The $1530 \mathrm{CE}$ eruption is representative of a typical subplinian (VEI 3) magmatic explosive eruption at SDG and is interpreted to be the most credible eruptive scenario for a future event (Boudon et al. 2008; Komorowski et al. 2008).

The $1530 \mathrm{CE}$ eruption began with phreatic explosions followed by partial collapse of the edifice that emplaced a debris avalanche (Komorowski et al. 2002, 2005; Boudon et al. 2008), which travelled at least $9 \mathrm{~km}$ in the South-West direction and reached the sea at Basse-Terre (all places referred to herein are located on Fig. 2). It then evolved into a short (ca. $1 \mathrm{~h}$ long) subplinian phase (with an intensity of between $5 \times 10^{6}$ and $2 \times 10^{7} \mathrm{~kg} / \mathrm{s}$; Komorowski et al. 2008, 2013). This phase produced coarse pumice and scoria fallout from a column inferred to have reached 16 to $18 \mathrm{~km}$ in height, as well as pumice and scoria-rich PDCs from column collapse.
Deposits from PDCs are found in a very few poorly preserved and ephemeral exposures scattered in different valleys around SDG's dome, notably in the Rivière du Carbet (East), Rivière Noire (West), Rivière Saint-Louis (North-West), and in the Rivière $d u$ Galion (South-Southwest), up to maximum distances of about 6-7 km (Boudon et al. 2008; Fig. 3). Following the subplinian phase, a short-lived period of violent strombolian activity occurred producing stratified scoria fall layers mostly to the North-East of the vent. The final phase of the eruption produced an andesite lava dome (ca. $50 \times 10^{6} \mathrm{~m}^{3}$ ) within the depression left by the partial edifice collapse at the onset of the eruption (Komorowski et al. 2002, 2005; Boudon et al. 2008). Interpretation of field data, considering erosion and weathering processes, the short distance between SDG's summit and the coastline $(9 \mathrm{~km})$, and the unknown mass of fine-grained fallout deposits in the sea and thus unaccounted for, suggests that PDC deposits from the $1530 \mathrm{CE}$ eruption account for $57 \%$ of the total mass erupted (Komorowski et al. 2013). Outcrops of pumice PDCs from older plinian (VEI 4) eruptions of SDG have been identified at distances of about $8 \mathrm{~km}$ from the vent (green stars in Fig. 3). It is likely that they might have reached further given the intense erosion that has

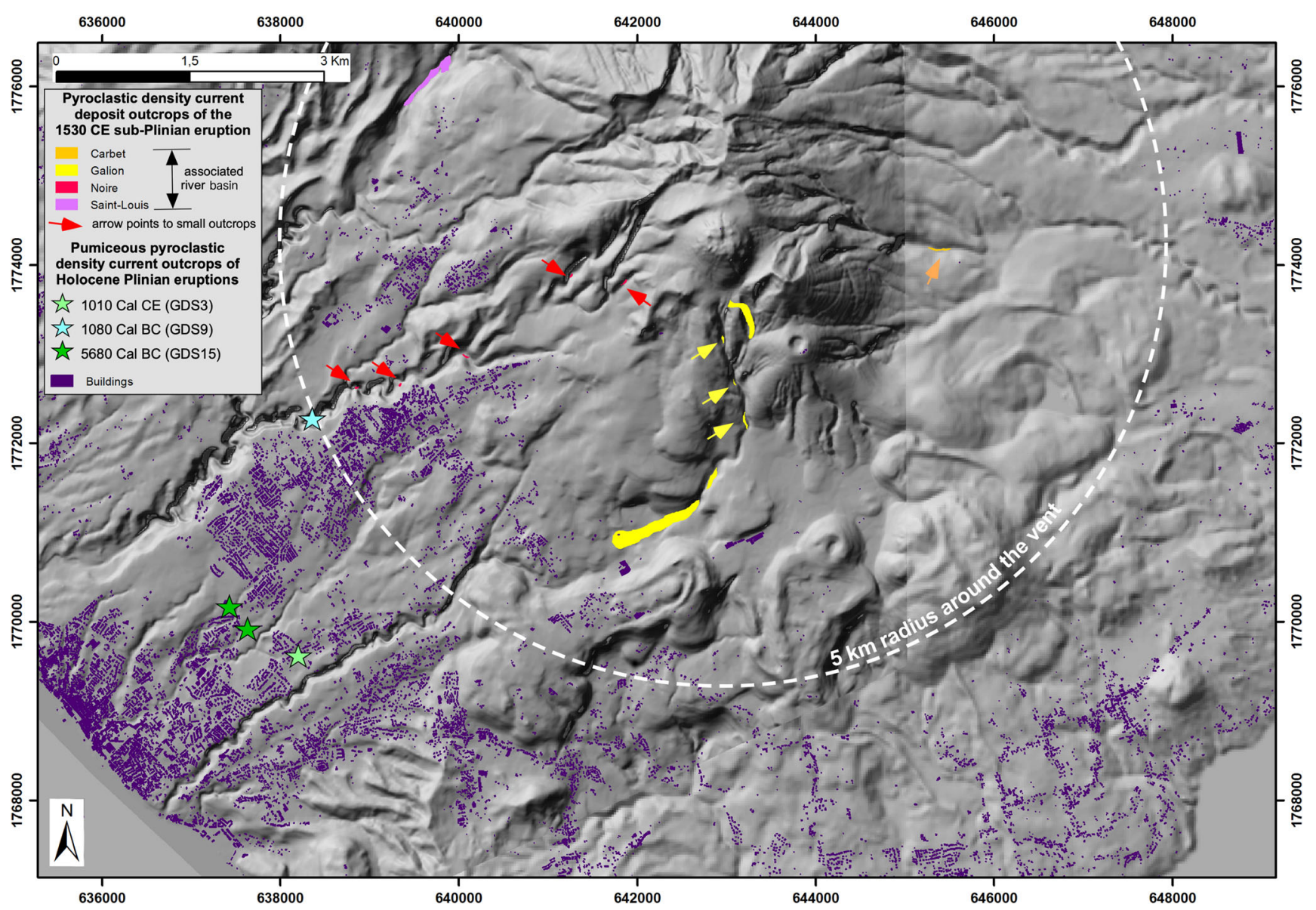

Fig. 3 Map of PDC outcrops and inferred eroded PDC deposits from the last major magmatic subplinian eruption at La Soufrière de Guadeloupe in 1530 CE (modified after Boudon et al. 2008; Komorowski et al. 2008;
Legendre 2012; Komorowski et al. 2013). The digital elevation model and building data are from BDAlti ${ }^{\circledR}$ and BDTopo ${ }^{\circledR}$ databases, IGN 
affected the deposits since their emplacement (Legendre 2012; Komorowski et al. 2013).

Owing to the complexity of the eruptive sequences of SDG and difficulties in reconstructing a complete eruptive record due to dense vegetation, erosion, and alteration processes (Legendre 2012), the quantitative assessment of volcanic hazards in Guadeloupe is still an ongoing, challenging, and urgent task. Indeed, seismic, fumarolic, and thermal unrest at SDG has been slowly increasing since 1992 (Komorowski et al. 2005; OVSG-IPGP 1999-2020). In April 2018, the unrest reached its highest level since the end of the 1976-1977 failed magmatic eruption (Moretti et al. 2020; OVSG-IPGP 19992020). Although the alert level has remained at yellow (vigilance), the increasing unrest has prompted reinforced surveillance by the Volcanological and Seismological Observatory of Guadeloupe and the decision by authorities to implement an exclusion zone for the general public to the most active areas of the summit (Préfet de la Région Guadeloupe 2019).

This work thus contributes to a volcanic risk assessment strategy in Guadeloupe initiated several years ago (Komorowski et al. 2005, 2008, 2013; Hincks et al. 2014; Legendre 2012; Peruzzetto et al. 2019; Leone et al. 2019), with the first integrated hazard map for SDG being produced by Komorowski et al. (2005). Subsequently a first attempt to characterize the eruptive behaviour in a systematic way was carried out by Komorowski et al. (2008), who defined a logical event tree for magmatic unrest and eruptions. Using this framework, and by means of a combined field study and numerical simulations, Komorowski et al. (2008) analysed the hazards associated to the tephra fallout phase in a subplinian scenario similar to $1530 \mathrm{CE}$ event. Considering the recurrence of PDCs in the volcanic history of SDG, and the evidence of PDC deposits in urbanized areas (Legendre 2012), it seems very likely that for such a future magmatic eruption, PDCs could affect, directly or indirectly, a very large part of the South of the island of Basse-Terre, where some 70,000 people live. Given the topography of the area and the geometry of rivers that drain the volcano and reach the inhabited areas, one of the most important issues of the hazard and impact assessment is to model the influence of the topography on the mobility and dynamics of the PDCs and the associated inundation areas.

We thus approach the dynamics of PDCs, and the associated hazards, by numerically simulating in $3 \mathrm{D}$ and time an eruptive scenario characterized by the collapse of a volcanic column and subsequent PDC propagation over the incised topography of the volcano. In particular, we aim at understanding which eruptive conditions would be able to generate PDCs attaining the distances where outcrops from the 1530 CE eruption have been found (Fig. 3). In addition, because poor deposit preservation makes it impossible to obtain a homogeneous picture of the areas potentially inundated by PDCs, we use numerical modelling to understand how the volcano summit topography distributes the mass of material from a collapsing column around the vent and into valleys. Finally, quantifying how PDCs would impact the inhabited zone on the volcano flanks has important implications in terms of hazard assessment, risk mitigation, and crisis response in the event of a future eruption.

\section{Subplinian eruption modelling and hazard assessment}

Following Komorowski et al. (2008) and Boudon et al. (2008), the last magmatic eruption of SDG in $1530 \mathrm{CE}$ is taken as a reference scenario for assessing hazards associated with PDC emplacement. The eruption followed the partial collapse of the edifice that resulted in the formation of a 500-m-wide horseshoe-shaped collapse structure open to the South and South-West and the emplacement of a debris avalanche deposit (Boudon et al. 2008; Komorowski et al. 2008; Legendre 2012). However, we here only consider the subplinian phase and, in particular, the stage of collapse of the volcanic column and generation of PDCs.

Defining the source parameters for an eruptive scenario based only on the interpretation of partial sedimentological records is a challenging task. Plinian and subplinian eruptions are characterised by a phase of formation of the convective plume and umbrella cloud, with associated tephra fallout deposits, and by simultaneous (or alternating) phases of column collapse and PDCs (Cioni et al. 2002). The height reached in the atmosphere by the convective column and umbrella can be estimated from the inversion of observable field data (e.g. maximum clast size isopleths of the fallout deposit or remote sensing data) using simplified models (e.g. Pyle 1989; Scott et al. 1996; Mastin et al. 2009; Burden et al. 2011; Bonadonna and Costa 2012; Biass et al. 2019) or numerical methods (Cerminara et al. 2015). For the 1530 CE eruption, the column height has been estimated at between 9 and $12 \mathrm{~km}$ from tephra fall deposits by Komorowski et al. (2008). This corresponds to an estimated peak mass eruption rate of between $5.5 \times 10^{6}$ and $1.3 \times 10^{7} \mathrm{~kg} / \mathrm{s}$, i.e. in the range of subplinian eruptions (Newhall and Self 1982; cf. Cioni et al. 2002). With new field data (Legendre 2012), the column height has been determined to have reached 16 to $18 \mathrm{~km}$, for a mass eruption rate on the order of $7 \times 10^{6}-2 \times 10^{7} \mathrm{~kg} / \mathrm{s}$, a volumetric flux of $4-7 \times 10^{3}$ $\mathrm{m}^{3} / \mathrm{s}$, and an estimated minimal eruption duration of $0.7 \mathrm{~h}$ (Komorowski et al. 2013). For realistic eruption conditions (volatile content between 2 and $5 \mathrm{wt} . \%$ and temperatures between 950 and $1100^{\circ} \mathrm{C}$ ), both one-dimensional (Wilson et al. 1980; Woods 1988; Ishimine 2006; Carazzo et al. 2010) and three-dimensional numerical models (Suzuki and Koyaguchi 2012; Koyaguchi and Suzuki 2018) show that mass eruption rates in this range lie at the threshold between a convective and collapsing plume regime, which can be termed a 
transitional or oscillating regime (Neri and Dobran 1994; Di Muro et al. 2004; Suzuki and Koyaguchi 2012). To reconstruct the mass eruption rate at the time of collapse during transitional regimes, we have assumed, based on Wilson et al. (1980), that this is equal to the maximum intensity achieved during the convective phase. However, the numerical investigations of Trolese et al. (2019) demonstrate that plume height is strongly reduced during partial collapse episodes, so that the mass eruption rate might be underestimated. Moreover, in some situations full collapse (boiling over or fountain collapse; Fisher and Heiken 1982; Druitt et al. 2002a; Sulpizio et al. 2014) of a subplinian column can be triggered by the downward collapse of the edifice into an emptying chamber to form a summit caldera. This might imply a significant increase of the eruption intensity (cf. Marti et al. 2000; Cioni et al. 2002) due to the sudden enlargement of the vent (cf. Wilson et al. 1980). Although there is no clear evidence for a summit caldera collapse at SDG during the $1530 \mathrm{CE}$ eruption, a sudden enlargement of the vent might have resulted as a consequence of an initial phase of partial lateral flank collapse. Moreover, geophysical imaging (i.e. electric conductivity and spontaneous potential; Brothelande et al. 2014; Rosas-Carbajal et al. 2016) indicate the presence of an arcuate vertical structure to the South-West and South of the current dome that may mark the relict margins of the explosion crater associated with the eruption within which the dome grew at the end of the eruption (Boudon et al. 2008). Overall, the structural features surrounding the current dome show a combination of an explosion crater and edifice collapse structure that is roughly circular and about $900 \mathrm{~m}$ in diameter. Therefore, we also considered a scenario with an enlarged vent diameter.

\section{Modelling of PDC dynamics and hazard}

During collapse regimes, the eruptive mixture at the time of collapse can be relatively dilute, especially in oscillating columns where it can have an average density as low as $\sim 10 \mathrm{~kg} / \mathrm{m}^{3}$, i.e. a particle volume concentration of less than $\sim 10^{-2}$ (Wilson et al. 1980; Woods 1988; Neri and Dobran 1994; Esposti Ongaro et al. 2002, 2008a; Suzuki and Koyaguchi 2012; Trolese et al. 2019). Nonetheless, PDCs manifest a steep vertical stratification in the proximal region around the vent, where breccias are often observed (Branney and Kokelaar 2002; Valentine and Sweeney 2018). Such PDCs can be described as a basal, concentrated layer overlain by an upper, more dilute (stratified) and more mobile ash cloud (cf. Doyle et al. 2010).

A common approach to studying the subsequent PDC dynamics and their hazard is to adopt homogeneous mixture, depth-averaged models, which have the advantage of a fast numerical solution (e.g. Patra et al. 2005; Shimizu et al. 2017; de' Michieli Vitturi et al. 2019). However, single-layer models always impose a dichotomy (and the need for a choice) between dominantly frictional (concentrated) or dominantly inertial (dilute) PDCs. In this regard, inertial flow models (Sparks 1976; Sparks et al. 1978; Bursik and Woods 1996; Dade and Huppert 1996) describe PDCs as relatively dilute (particle concentration $<10^{-2}$ ), turbulent gas-particle flows, which lose mass, increase in buoyancy, and eventually stop their horizontal motion, lifting off as a consequence of particle settling and air entrainment. Such models are more suited to modelling PDCs in the absence of a significant topographic slope or for very long runouts such as those associated with high aspect ratio ignimbrites. In such cases, the basal, concentrated layer acts as a depositional system and does not control PDC dynamics (the transport system; Fisher et al. 1993; Giordano and Doronzo 2017). Such an approach has also been applied to calderas, where the average volcanic slope is negligible (Brand et al. 2014; Neri et al. 2015a, b; Esposti Ongaro et al. 2016). At the other end-member, frictional flow models (Patra et al. 2005; Kelfoun et al. 2009; Doyle et al. 2008; Roche et al. 2011) describe PDCs as concentrated granular flows (with particle volume concentrations of $>10^{-1}$ ), controlled by frictional forces. They are more suited to low aspect ratio PDCs, often confined to the volcano flanks, or to describe the behaviour of the basal part of a stratified PDC. Most of the difficulties in the physical description of PDCs is related to the interplay between these two end-members in natural (Druitt et al. 2002b; Ogburn et al. 2014; Bernard et al. 2014; Capra et al. 2016) and laboratory PDCs (Breard and Lube 2017), where the multiphase nature of the mixture also poses significant physical and mathematical challenges (Pitman and Le 2005; Pudasaini and Mergili 2019). An attractive and promising alternative to single-layer models is provided by two-layer depth-averaged models (Doyle et al. 2010; Kelfoun 2017; Shimizu et al. 2019; Gueugneau et al. 2019), in which PDC stratification is simplified into a concentrated, basal layer underlying a dilute ash cloud. However, in these models, it can be challenging to calibrate a priori empirical mass, momentum, and energy exchanges between the two layers. This adds to the difficulty of calibrating rheological models for both the concentrated and turbulent layers and to properly set the source conditions for column collapse.

Here, we use the three-dimensional, multiphase flow model PDAC (i.e. Pyroclastic Dispersal Analysis Code; Neri et al. 2003; Esposti Ongaro et al. 2007; Carcano et al. 2013) to numerically simulate the development, instability, and collapse of a subplinian eruption column and the generation and propagation of PDCs over the topography around SDG. All model equations and the main underlying assumptions are summarized in Appendix 1. The advantage of using nonequilibrium multiphase flow models is that they offer a comprehensive description of stratified PDCs (Esposti Ongaro et al. 2008b, 2012; Esposti Ongaro et al. 2016; Dufek and Bergantz 2007b; Dufek 2015; Benage et al. 2016). In particular, 3D models can describe PDC proximal stratification, 
formation of the basal layer by particle settling, and generation of an overlying ash cloud due to shear flow mechanisms.

The reliability of the PDAC model in describing the main large-scale behaviour of volcanic plumes, for the range of mass eruption rates apparent here, has been demonstrated by a 3D plume model inter-comparison study (Costa et al. 2016; Suzuki et al. 2016; Esposti Ongaro and Cerminara 2016). However, a quantitative, rigorous evaluation of modelrelated uncertainty on a full eruption scenario involving plume formation, instability, and PDC generation is not yet possible. This is a more general issue, related to the validation of numerical models in volcanology (Oreskes et al. 1994; Esposti Ongaro et al. 2020). We thus base our discussion on the relatively large number of 3D numerical simulations performed in this study, with input conditions derived from field work carried out at SDG and published in Boudon et al. (2008), Komorowski et al. (2008, 2012, 2013), and Legendre (2012). In evaluating the reliability of our results and the potential effect of the adopted numerical approximations on the model output, we also rely on our 2D/3D numerical simulations at Vesuvius (Esposti Ongaro et al. 2002, 2008a; Neri et al. 2007), Soufrière Hills, Montserrat (Esposti Ongaro et al. 2008b), Campi Flegrei (Todesco et al. 2006; Esposti Ongaro et al. 2010), Mount St. Helens (Esposti Ongaro et al. 2012), and on similar modelling works by Dufek and Bergantz (2007a, b) and Benage et al. (2016).

\section{Simulation assumptions and source parameters}

Our modelling assumes a sustained event, i.e. stationary conditions at the vent producing a collapsing column. In Appendix 2, we also discuss the application of the method to a single, impulsive explosion. Steady-state boundary conditions are imposed at the vent, coinciding with the exit section of the crater. We initially assume an average mass flow rate of $7 \times 10^{6} \mathrm{~kg} \mathrm{~s}^{-1}$ ejected from a circular vent located on the present summit of the SDG dome, as based on Komorowski et al. (2008). Initial temperature was set to $1050 \mathrm{~K}\left(777^{\circ} \mathrm{C}\right)$ and water content to $2 \mathrm{wt} . \%$, resulting in a mixture density of around $12 \mathrm{~kg} / \mathrm{m}^{3}$. Although the water content is lower than the $5 \mathrm{wt} . \%$ estimated from petrological analysis of the erupted materials (Boudon et al. 2008; Pichavant et al. 2018), our previous studies (Esposti Ongaro et al. 2008a) show that a value of 2 wt. $\%$ is the upper threshold for which subplinian eruption plumes with mass flow rates and temperatures in the investigated range can collapse and produce PDCs. It is also worth recalling that reduction of volatile content in the gas-pyroclast eruptive mixture is possible by many mechanisms, including gas entrapment in pumice (Kaminski and Jaupart 1998) and permeable degassing (La Spina et al. 2017).
The granulometry of juvenile particles was derived from data given in Komorowski et al. (2008) by adopting three particle classes with diameters of $1000 \mu \mathrm{m}(50 \mathrm{wt} . \%)$, $250 \mu \mathrm{m}(24 \mathrm{wt} . \%)$, and $30 \mu \mathrm{m}$ (26 wt.\%), and densities of 1200,2000 , and $2,600 \mathrm{~kg} / \mathrm{m}^{3}$, respectively. Although this granulometry is finer than the actual subaerial deposit of the 1530 CE eruption of SDG, it represents a compromise between the need to account for a relatively coarse component of the pyroclastic phase and the capability of our numerical model to treat coarse-grained phases. Moreover, the choice of a finer granulometry is justified by the fact that a large part of the material produced in subplinian eruptions is fine-grained and deposited distally (Sparks and Walker 1977; Marti et al. 2016), in our case in the sea where it is not easily accessible and thus cannot be included in estimates of the total grain size distribution. The three particulate phases are initially in mechanical and thermal equilibrium with the gas, but they are characterized by different degrees of coupling with the carrier fluid flow, so that non-equilibrium phenomena (between gas and particles and between different particles) developing during the eruption can be analysed with the model. Input parameters for grain size distribution are given in Table 1.

Four scenarios have been selected, named SP1 through SP4, whose main input parameters are given in Table 2 . Input parameters have been set to cover the estimated range of mass eruption rate and water content. A list of simulations performed to assess the robustness and sensitivity of the results to the numerical discretization and boundary conditions is given in Appendix 1.

Simulation SP1 has a vent radius of $38 \mathrm{~m}$ and an exit velocity of $127 \mathrm{~m} / \mathrm{s}$. It was run over a $6 \times 6 \mathrm{~km}^{2}$ digital elevation model centred on the summit area with uniform horizontal resolution of $10 \mathrm{~m}$. We used a non-uniform rectilinear 3D computational grid with horizontal resolution of 10 $\mathrm{m}$ in the area around the vent and $50 \mathrm{~m}$ at the North, South, East, and West boundaries, and $20 \mathrm{~m}$ vertical grid size up to $1500 \mathrm{~m}$ a.sl., increasing up to $200 \mathrm{~m}$ at the top of the domain $(12 \mathrm{~km})$. The position of the vent was placed at [642985;

Table 1 Properties and mass/volume fractions of solid particle phases (named P1, P2, and P3) used to represent the input grain size distribution for numerical simulations SP1-SP4 in Table 2. Grain size data are taken from Komorowski et al. (2008)

\begin{tabular}{lllll}
\hline Phase & Gas & P1 & P2 & P3 \\
\hline Diameter $[\mu \mathrm{m}]$ & n.a. & 1000 & 200 & 50 \\
Density $\left[\mathrm{kg} / \mathrm{m}^{3}\right]$ & 0.21 & 1200 & 2000 & 2600 \\
Bulk density $\left[\mathrm{kg} / \mathrm{m}^{3}\right]$ & 0.21 & 6.0 & 3.0 & 3.12 \\
Mass fraction $[\mathrm{wt} \%$ \% $]$ & 1.7 & 48.7 & 24.3 & 25.3 \\
Relative solid mass fraction & n.a. & 49.5 & 24.8 & 25.7 \\
Volume fraction & 0.9923 & 0.0050 & 0.0015 & 0.0012 \\
\hline
\end{tabular}


Table 2 Input parameters for the four simulated scenarios

\begin{tabular}{lllll}
\hline & SP1 & SP2 & SP3 & SP4 \\
\hline Input & & & & \\
$\quad$ Inlet radius $[\mathrm{m}]$ & 38 & 45 & 52 & 104 \\
Inlet velocity $[\mathrm{m} / \mathrm{s}]$ & 127 & 90 & 70 & 70 \\
Gas pressure $[\mathrm{Pa}]$ & $10^{5}$ & $10^{5}$ & $10^{5}$ & $10^{5}$ \\
Mixture density $\left[\mathrm{kg} / \mathrm{m}^{3}\right]$ & 12 & 12 & 12 & 12 \\
Mixture temperature $[\mathrm{K}]$ & 1050 & 1050 & 1050 & 1050 \\
Water content $[\mathrm{wt} . \%]$ & 2 & 2 & 2 & 2 \\
Mass flow rate $[\mathrm{kg} / \mathrm{s}]$ & $7 \times 10^{6}$ & $7 \times 10^{6}$ & $7 \times 10^{6}$ & $2.8 \times 10^{7}$ \\
Output & & & & \\
Estimated percentage of collapse $( \pm 10 \%)$ & $50 \%$ & $70 \%$ & $90 \%$ & $90 \%$ \\
\hline
\end{tabular}

1774280] in UTM 20N WGS84 Cartesian projection. Simulation SP2 has the same mass eruption rate and mixture density as SP1; however, the vent radius is $16 \%$ larger (an increase from 38 to $45 \mathrm{~m}$ ). As a consequence, exit velocity is reduced to $90 \mathrm{~m} / \mathrm{s}$. The domain is extended to $11 \times 11 \mathrm{~km}^{2}$, with the same resolution $(10 \mathrm{~m})$ at the vent. Simulation SP3 also has the same mass eruption rate of $\mathrm{SP} 1$; however, the vent radius is $37 \%$ larger $(52 \mathrm{~m})$. As a consequence, exit velocity is further reduced to $70 \mathrm{~m} / \mathrm{s}$. The computational domain is extended to $20 \times 12 \mathrm{~km}^{2}$ in the horizontal directions, and the horizontal cell size around the vent is $20 \mathrm{~m}$ to keep the computational cost manageable. However, we made simulations at $10 \mathrm{~m}$ on a reduced domain to ensure that the main features are captured at the lower resolution (see Table 3). Finally, simulation SP4 has an increased mass eruption rate, four times larger than SP3 (i.e. $2.8 \times 10^{7} \mathrm{~kg} / \mathrm{s}$ ), with a vent radius twice as large $(104 \mathrm{~m})$, but with the same exit velocity and the same eruptive source parameters. Such a scenario might represent the final summit crater collapse stage during a subplinian event and should be considered as an extreme but credible scenario for the culminating phase of the eruption.

Occurrence of partial edifice collapse at the onset of, or during, a magmatic eruption can have profound consequences on the morphology of the vent that can lead to its enlargement and, thus, promoting full collapse of the eruptive column (as first demonstrated with a mathematical model by Wilson et al. 1980). Indeed, shortly after the onset of the $1530 \mathrm{CE}$ eruption, the edifice partially collapsed to the South leading to the emplacement of an $80 \pm 40 \times 10^{6} \mathrm{~m}^{3}$ debris avalanche deposit that reached the sea and left a large ca. 500-m-wide horseshoeshaped crater open to the South and South-West (Boudon et al. 2008; Fig. 3). Komorowski et al. (2005) and Legendre (2012) have shown that eight out of the nine edifice collapse events that occurred in the last 9150 years at SDG were associated with magmatic eruptions, and four of them $(50 \%)$ were associated with major explosive phases (subplinian or plinian). Increase of the mass flow rate by a factor of four in simulation SP4 can represent the effects produced by an asymmetric collapse, focussing the whole pyroclastic flow mass to one specific quadrant. We show in Appendix 3 that the resulting maps of PDC invasion are comparable when the same mass flow per unit of angle is considered. Such asymmetric subplinian column collapse has been shown to have favoured the formation of highly mobile although low-volume pumiceous pyroclastic flows in one main direction during the 2010 multiphase eruption of Merapi volcano (Komorowski et al. 2015). Clearly, such focussing of the mass in one or a few river valleys favours efficient mobility and longer runout than expected in the case of such small-volume PDCs.

To describe the column regime, we adopt the same approach used for Vesuvius by Esposti Ongaro et al. (2008a) and by Trolese et al. (2019), where the transition from the fully convective to fully collapsing regimes was quantitatively characterized by the percentage of collapsing mass (i.e. the ratio between the maximum mass collapse rate and the mass eruption rate at the vent). These studies, along with Esposti Ongaro et al. (2016), provided evidence that the percentage of collapse is the most important parameter controlling PDC propagation.

\section{Numerical simulation results}

\section{Partial collapse scenarios}

Numerical simulations describe in $3 \mathrm{D}$ the formation of the volcanic jet, its instability and partial collapse, resulting in the simultaneous formation of a sustained plume and PDCs. In scenario SP1 (Fig. 4), partial collapse starts at about $35 \mathrm{~s}$ after the onset of the subplinian eruptive phase, while the 
collapsing portion of the plume reaches the foot of the eruptive column at about $50 \mathrm{~s}$. At $100 \mathrm{~s}$ (Fig. 4a), incipient PDCs are still confined within the summit area while the central convective plume develops. At $200 \mathrm{~s}$ (Fig. 4b), the turbulent, convective part of the plume has reached a height of about $9 \mathrm{~km}$ above the vent, while PDCs start to propagate radially into valleys. At $300 \mathrm{~s}$ (final simulation time; Fig. $4 \mathrm{c})$, the plume has reached the top of the domain at $12 \mathrm{~km}$, while PDCs have almost stopped in lateral valleys. Fine ash elutriated from PDCs contributes to the formation of proximal co-ignimbrite plumes that merge with the main central plume. Isosurfaces of particle concentration (Fig. 4c) highlight the role of the near-vent topography in controlling the PDC propagation. In particular, PDCs are not able to overcome the topographic barriers on the North-West side of the summit, so that these flows are diverted into South-West valleys, along the $\mathrm{Nez}$ Cassé ridge (Fig. 2). Analogously, the steep valley to the South is the main collector of all PDC developing towards South and Southeast, where fastmoving $(10-15 \mathrm{~m} / \mathrm{s})$ currents form. The most concentrated PDC propagates along the Eastern valley.

In scenario SP2, characterized by a lower exit velocity and larger vent radius, the height of the momentum-driven jet decreases due to the lower velocity, leading to a lower collapse height. In Fig. 5a, b, this is represented by the isosurface of $10^{-4}$ particle concentration, whose maximum elevation decreases from about 2500 to $1500 \mathrm{~m}$ above the summit (from
4000 to $3000 \mathrm{~m}$ above the sea level). The computed percentage of collapse is about $70 \%$, which is still in the regime of an oscillating column. Pyroclastic density currents are mostly directed to the South-West, South, and Eastern sectors, but their runout after $300 \mathrm{~s}$ is limited to the proximal region (within $<2-3 \mathrm{~km}$ of the vent). At this point, PDCs have almost completely stopped moving horizontally and revert to buoyant clouds. At this stage, air entrainment is very effective in diluting the PDC and lowering its temperature. Although up to $70 \%$ of the mass is collapsing, a large fraction is rapidly elutriated by proximal co-ignimbrite plumes developing as soon as the collapsing portion of the plume impacts the ground. This occurs all around the vent, so that only about $20 \%$ of the total erupted mass feeds PDCs.

\section{Full collapse scenario}

The input conditions of SP3 produce a regime of almost total, stationary collapse (about $90 \%$ of the mass collapsing). The height of the jet is further lowered to about $500 \mathrm{~m}$ above the summit, and the structure of the eruptive column is significantly different, with a pyroclastic fountain above the vent that isotropically feeds PDCs, which spread radially all around the vent (Fig. 6). As observed at Vesuvius by Esposti Ongaro et al. (2008a) and by Trolese et al. (2019), this regime feeds more concentrated and more mobile PDCs, which
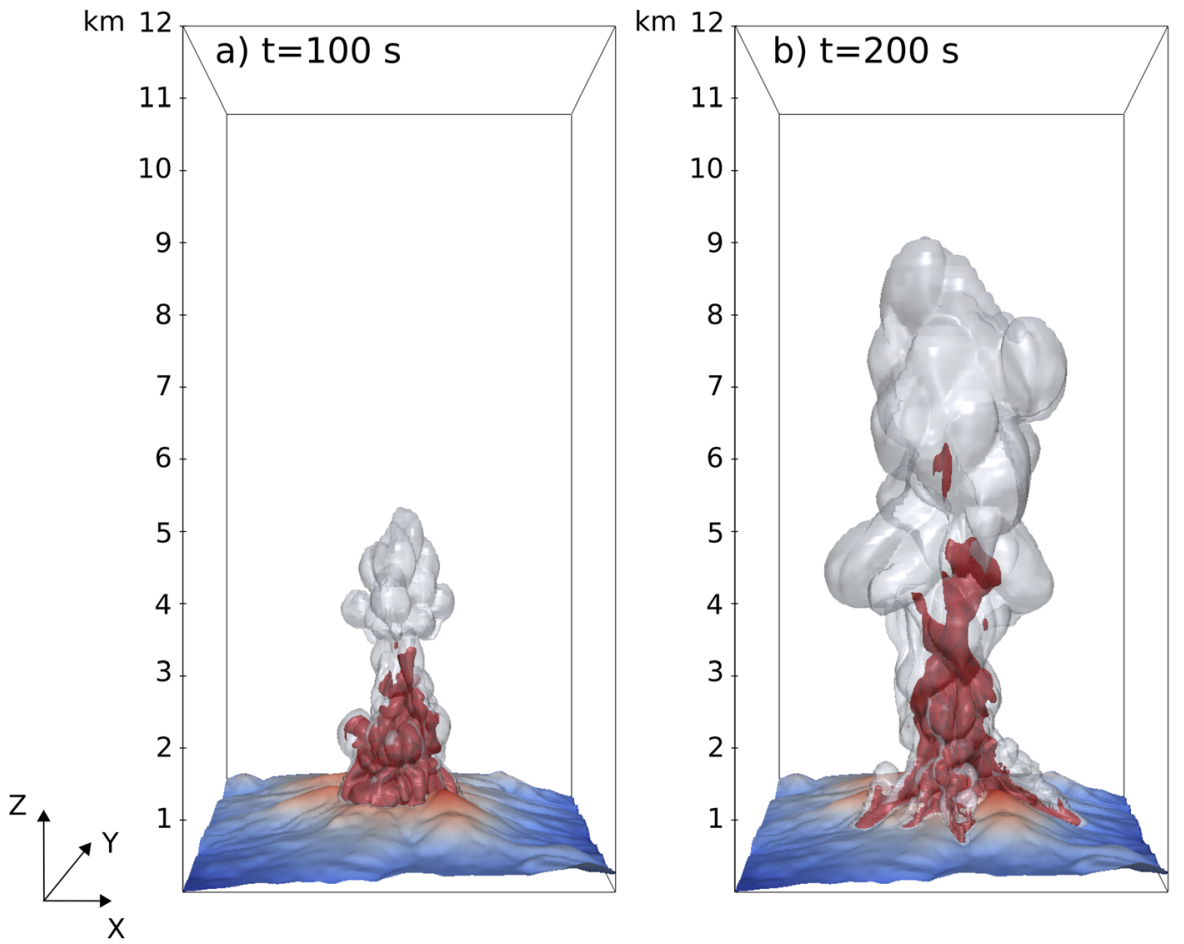

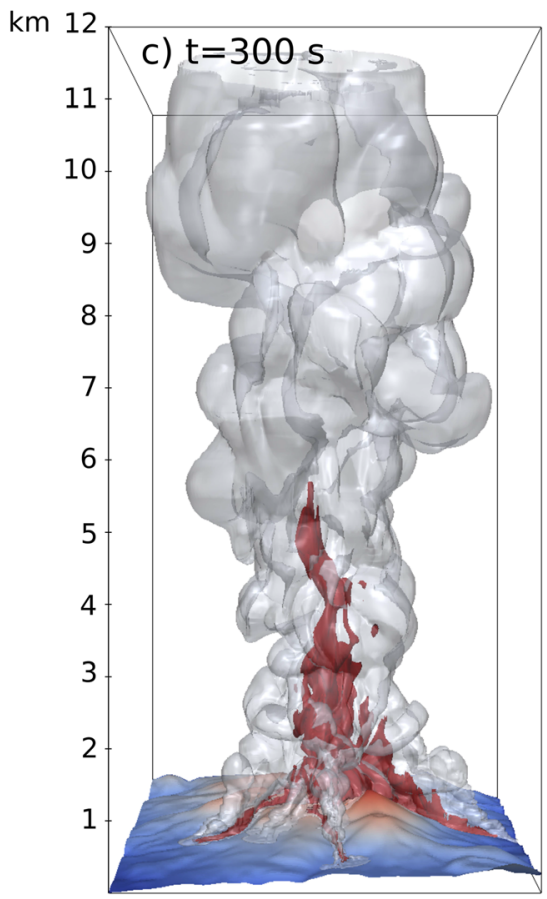

Fig. 4 Simulation of a subplinian eruption column with $50 \%$ of collapse and formation of channelized PDCs on the 3D topography (run SP1, Table 1). a $t=100 \mathrm{~s}, \mathbf{b} t=200 \mathrm{~s}$, and $\mathbf{c} t=300 \mathrm{~s}$, from the beginning of the collapse phase. Coloured zones are isosurfaces that represent fine ash $\left(50 \mu \mathrm{m}\right.$ diameter) volume concentrations of $10^{-5}$ (red, internal) and $10^{-7}$ (grey, transparent external). The $X$-axis is oriented West-East, and $Y$ is oriented South-North 
form stratified currents with higher basal particle concentration, larger inertia, and greater runout. Even in this case, however, PDCs are not able to overcome the topographic obstacles on the Northern side of the flank collapse structure or major scarps around the summit and are mostly focussed (by topography) towards the South, West-Southwest, and East.

Simulation SP4 (Fig. 7) also displays a regime of almost total collapse (larger than 90\%). Because of the increased mass flow rate, PDCs are of higher velocity and concentration and have a much longer runout. To the South-West, the collapsed mass is deflected by the Nez Cassé ridge and move down the Savane à Mulets area towards the town of SaintClaude (Fig. 2). Pyroclastic density currents initially branch and follow two main directions (one main stream in the Rivière Noire valley and a second, minor stream through the Bains-Jaunes area; Fig. 2), but they eventually merge after about $2 \mathrm{~km}$. About $300 \mathrm{~s}$ after the beginning of the collapse phase, PDCs have reached the inhabited region of St. Claude and become branched along the main valleys. At the same time, a large part of the collapsed mass is conveyed along the Riviere $d u$ Galion valley to the South into a narrow valley section (the Chute du Galion; Fig. 2), and branches into two main flows. The first eventually merges South of the town of Saint-Claude (Rivière Dugommier valley) with the SouthWest branch, while the second forms a channelized PDC propagating 6-7 km South from the vent, overtopping the Palmiste ridge to flow down towards the town of TroisRivières, along the Rivière du Petit-Carbet valley (Fig. 2). To the East, the main branch is directed along the Rivière $d u$
Carbet (Grand Carbet) valley, towards the headland of Pointe-du-Carbet (Fig. 2), where it is able to reach the sea (about $10 \mathrm{~km}$ from the vent). At the coast, the flow still possesses a significant dynamic pressure $(>1 \mathrm{kPa})$. A minor branch is channelized along the Rivière $d u$ Perou, but extends no more than $3 \mathrm{~km}$.

\section{PDC invasion maps}

Maps of PDC invasion were plotted by interpolating the 3D numerical results on isosurfaces at constant height above the topography. We take the first cell above the topography as representative of ground-level PDC conditions. Ground-level values are thus average values for the first $20 \mathrm{~m}$ above the topography (10 m for fine mesh simulations; Appendix 1). Such an averaging is implicit in the adopted finite volume computational technique and numerical grid. We use temperature and dynamic pressure (i.e. the kinetic energy per unit of volume) as the two most significant variables for hazard assessment (Esposti Ongaro et al. 2002; Gurioli et al. 2005). Dynamic pressure is calculated as $P_{\mathrm{dyn}}=\frac{1}{2} \rho_{m}\left|\boldsymbol{v}_{m}\right|^{2}$, where $\rho_{m}$ and $\left|\boldsymbol{v}_{m}\right|^{2}$ are the mixture density and magnitude of the velocity in the first computational cell above the topography. Maps of temperature are shown at the final simulation step (i.e. after $300 \mathrm{~s}$ for SP1, $380 \mathrm{~s}$ for SP2, $550 \mathrm{~s}$ for SP3, and $800 \mathrm{~s}$ for SP4). This is the time at which the most concentrated (basal) part of the current stops to advance. Following past simulation experiments and comparisons with real PDC events (e.g. Esposti Ongaro et al. 2008b, 2012) suggests that
Fig. 5 Comparison between 3D numerical simulations of the partial collapse of an eruptive column in a subplinian scenario with different collapse percentages. a Run SP1, 50\% collapse. b Run SP2, 70\% collapse. Isosurfaces represent total particle concentration in the atmosphere of $10^{-4}$ (inner, orange) and $10^{-6}$ (outer, grey), $280 \mathrm{~s}$ after the beginning of the simulation. The horizontal $X$-axis gives the UTM (West-East) coordinates, $Z$ is the elevation above sea level, in metres
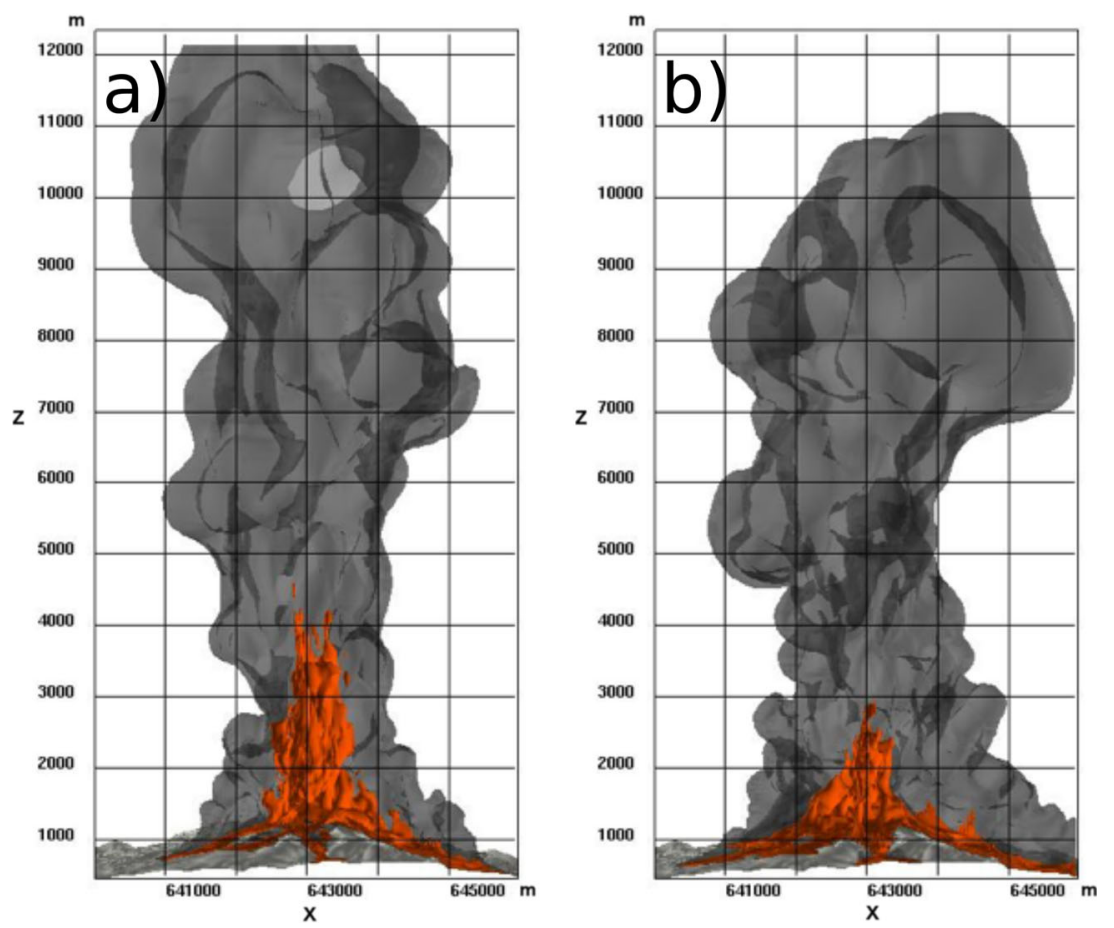
Fig. $63 \mathrm{D}$ sequence of fully collapsing (>90\%) subplinian eruption (run SP3) at a $t=100 \mathrm{~s}, \mathbf{b}$ $t=200 \mathrm{~s}$, and $\mathbf{c} t=380 \mathrm{~s}$, after the beginning of the collapse phase. The colour scale represents the volume concentration of the fine ash (diameter $50 \mu \mathrm{m}$ ) on a logarithmic scale
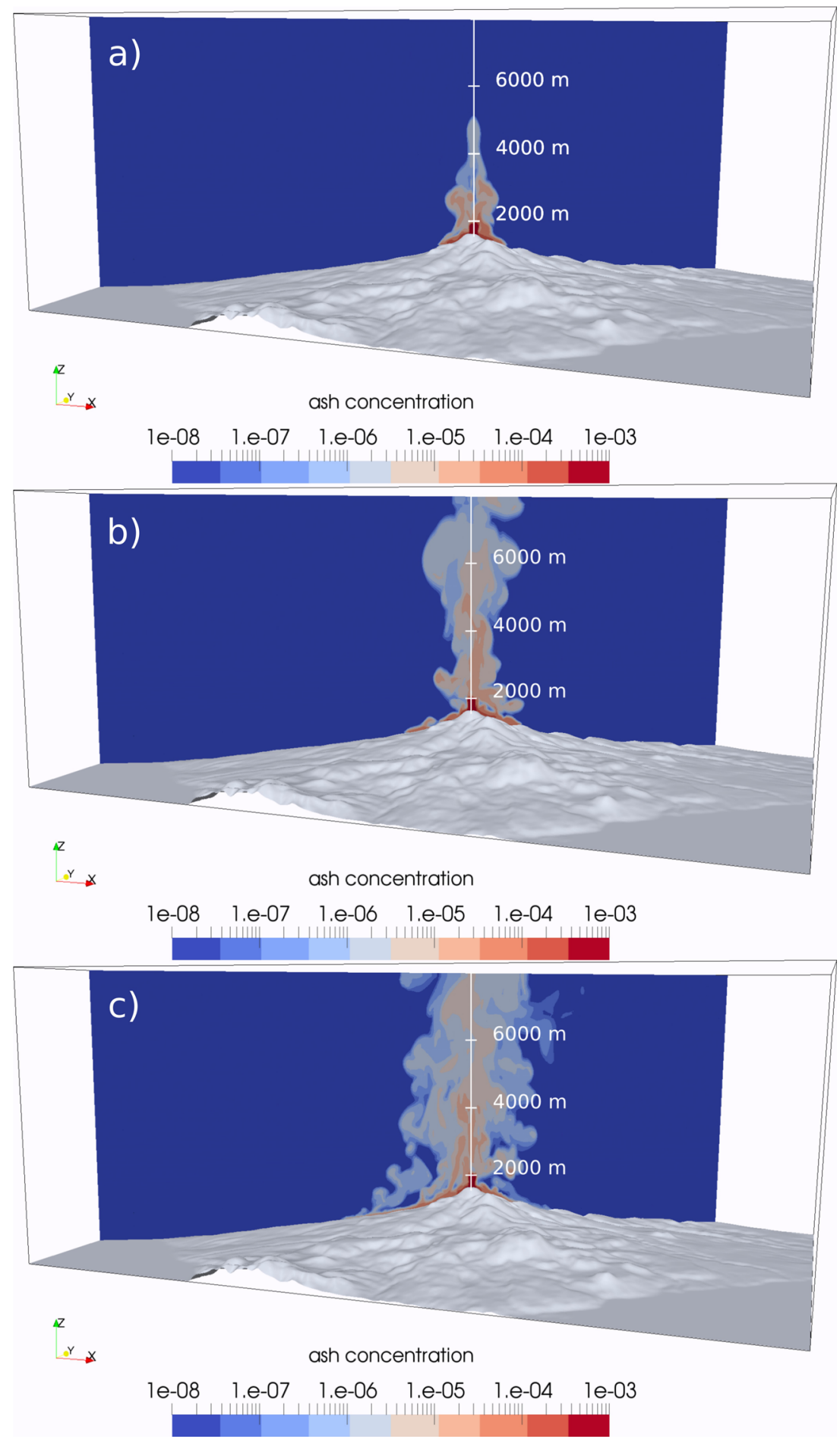

this is the best estimate of the actual PDC runout, even though the dilute cloud is still capable of slow advance, especially in the absence of wind and atmospheric turbulence in the model description. For dynamic pressure, we plot the maximum value reached at each grid point during the simulation.

Maps of mixture temperature at $10 \mathrm{~m}$ above the topography are given in Fig. 8a-d for simulations SP1, SP2, SP3, and SP4.
Partial collapse events (SP1 and SP2) have very similar distributions (Fig. 8a,b), with a more pronounced branch to the North-West in SP2. Both scenarios are characterized by oscillating columns with very efficient air entrainment and flow cooling, generating PDCs that are quickly stopped by air drag and lift-off. There are no concentrated PDCs beyond a distance of about $2.5 \mathrm{~km}$ to the South and South-West, and after 

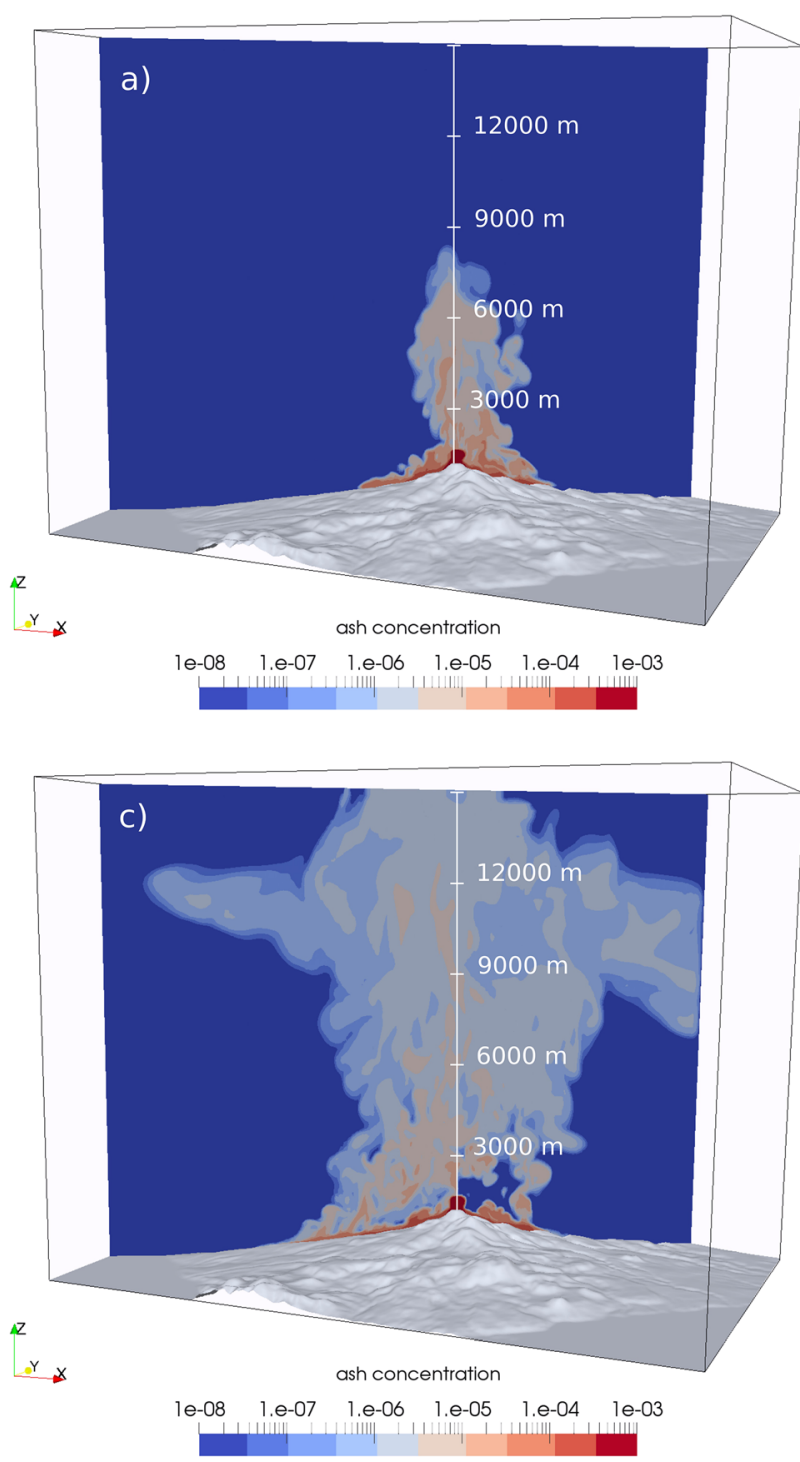

Fig. 7 3D sequence of full (>90\%) collapse, with increased mass eruption rate of about $3 \times 10^{7} \mathrm{~kg} / \mathrm{s}$ (run SP4) at a $t=200 \mathrm{~s}, \mathbf{b} t=400 \mathrm{~s}$, $\mathbf{c} t=600 \mathrm{~s}$, and $\mathbf{d} t=800 \mathrm{~s}$ after the beginning of the collapse phase. The

about $3 \mathrm{~km}$ to the East-South-East. Their impact on inhabited regions is consequently quite limited. Full collapse, boiling over scenarios SP3 and SP4, on the contrary, are able to spread PDCs over the entire South-West sector and towards the East (Fig. 8c,d), with some topographic channelling and proximal morphological control. The PDCs generated by boiling over are able to maintain their initial high temperature (above 700 $\mathrm{K}$, or $427^{\circ} \mathrm{C}$ ) in the basal, more concentrated part of the flow. The only sectors preserved from PDC invasion are towards the South-East, a result of the sheltering effect of the EchelleCiterne complex, and to the North, which is protected by Carmichael and Grande Découverte edifices.

For simulations SP1 and SP2, dynamic pressure maps do not show values of greater than $1 \mathrm{kPa}$ outside of the summit area and the low values recorded in the simulation (mostly
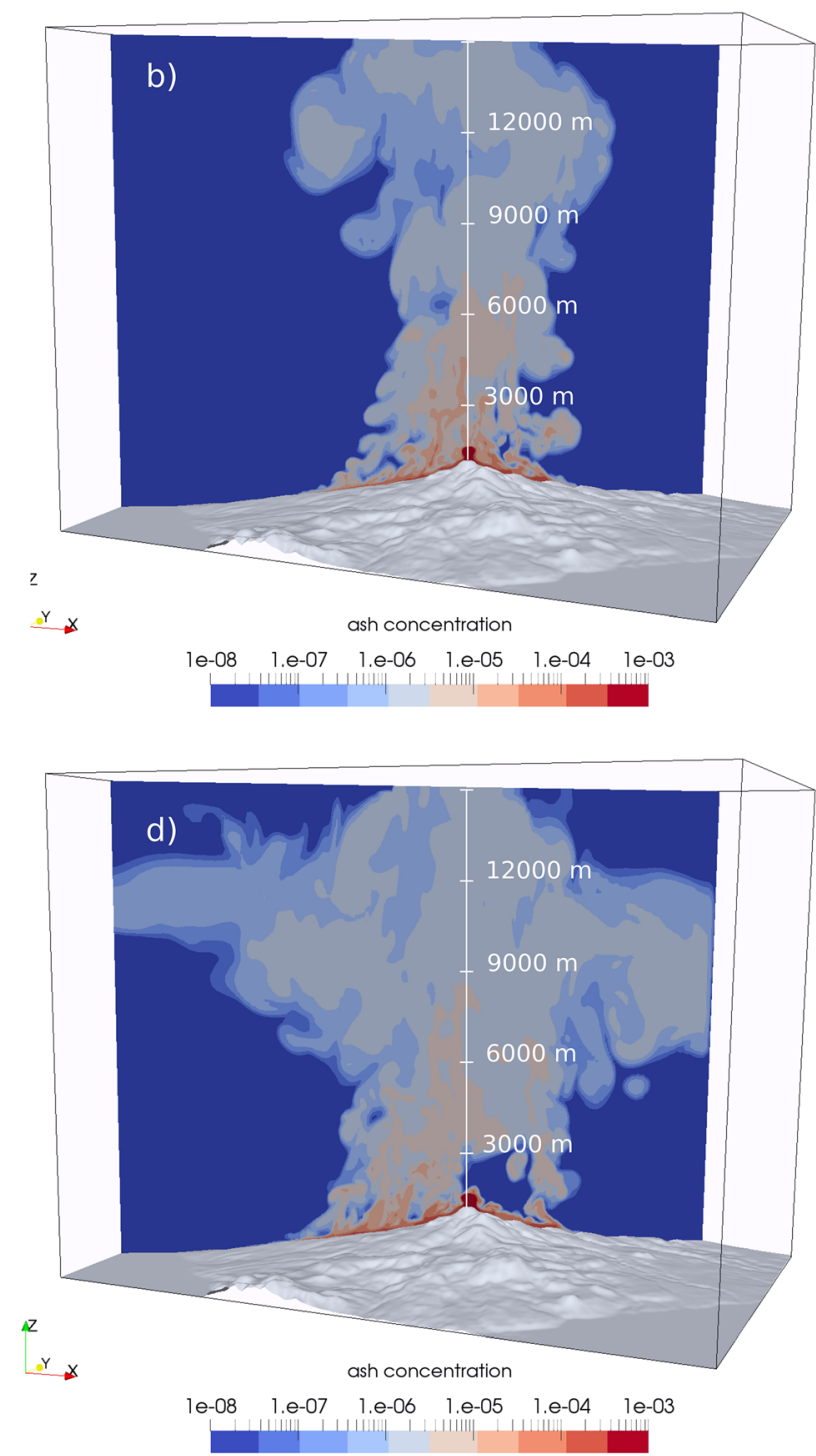

colour scale represents the volume concentration of the fine ash (diameter $50 \mu \mathrm{m})$ on a logarithmic scale

associated with velocity of atmospheric air) make the maps extremely noisy, so that we do not present the maps here as they are meaningless. As a reference, a dynamic pressure of $1 \mathrm{kPa}$ is sufficient to break windows, whereas at $10 \mathrm{kPa}$ failure of reinforced masonry can be expected (Jenkins et al. 2010, 2013a). Figure 9 represents the maximum dynamic pressure for runs SP3 and SP4, with values lower than $1 \mathrm{kPa}$ filtered out. For SP3, dynamic pressures above $10 \mathrm{kPa}$ are estimated only close to the summit and along the Rivière $d u$ Carbet valley, whereas in the other valleys and in the proximal region (within 2-3 km from the vent) values up to $5 \mathrm{kPa}$ can be expected (Fig. 9). Dynamic pressures of up to $3 \mathrm{kPa}$ are estimated in the more distal ( $>4 \mathrm{~km})$ and inhabited regions, including in the town of St. Claude. For SP4, the full collapse regime and the increased mass flow rate make the area of 


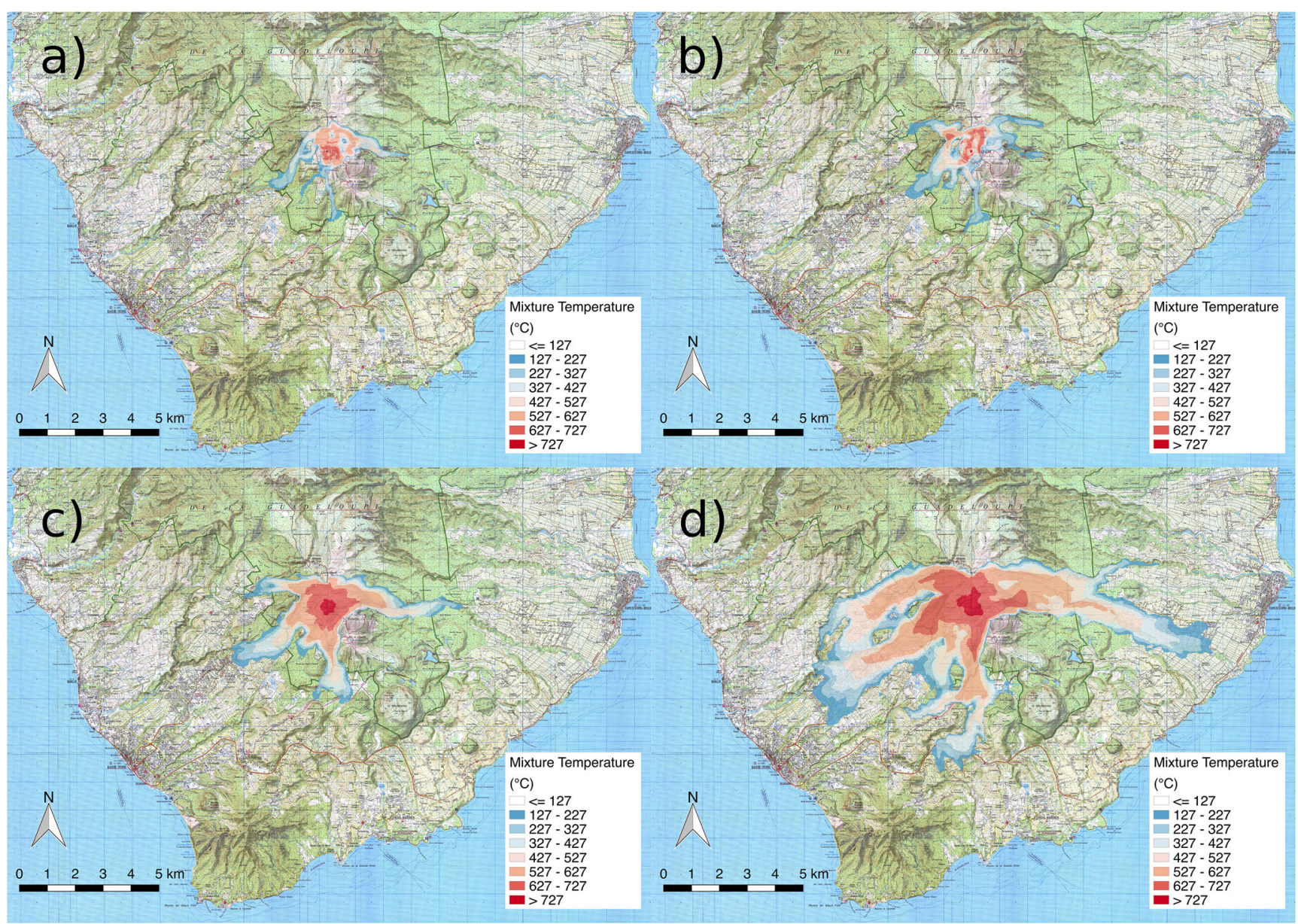

Fig. 8 Final maps of mixture temperature superposed to the IGN cartography, showing the inhabited regions around the volcano. Maps are given for simulations a SP1, b SP2, c SP3, and d SP4

significant impact much wider (cf. Fig. 9a, b). To the West, St. Claude and Matouba would be subject to PDCs with dynamic pressures exceeding $10 \mathrm{kPa}$ at the edge of the town closest to the vent and $>5 \mathrm{kPa}$ over most of the town (Fig. 9b). Pyroclastic density currents with dynamic pressures of $>$ $1 \mathrm{kPa}$ would extend as far as the town of Basse-Terre, and to the South, dynamic pressures of $>1 \mathrm{kPa}$ is predicted at distances out to about $6 \mathrm{~km}$. To the East, both the Rivière $d u$ Carbet and Rivière du Perou valleys would be affected, with the inhabited region of the town of Capesterre-Belle-Eau impacted heavily by dynamic pressures of $>3 \mathrm{kPa}$. The region affected by dynamic pressures of $>1 \mathrm{kPa}$ extends almost to the coast down the Rivière du Carbet valley (Fig. 2).

\section{Control of proximal morphology on PDC distribution}

The distribution of PDCs around the vent is controlled by the morphology of the volcano summit (Fig. 2b). In our simulations, we impose a circular vent and homogeneous conditions with no wind, so that partial and total collapses intermittently feed PDCs uniformly around the vent Pyroclastic density currents are initially confined by the walls of the flank collapse structure, but the progressive superposition of multiple collapsing events then favours the propagation of PDCs beyond this limit. In Fig. 10, we show the temporal evolution of the mass conveyed in the different sectors of the volcano for simulations SP3 and SP4.

The main topographic obstacle in the Northern sector is represented by Carmichael and Grande Découverte edifice in the North-West sector and the Montagne de la Capesterre edifice in the North-East sector (Fig. 2), which in our simulations prevents the propagation of PDCs to the North (only about $2 \%$ of the collapsing mass is channelized along the Rivière St Louis valley in simulation SP4). However, part of the collapsed mass (11\% and $15 \%$ of the collapsing mass in scenarios SP3 and SP4, respectively) is able to surmount the first topographic barrier and is channelized to the West towards the town of Matouba. Towards the East, PDCs are confined by the Echelle edifice and are channelized along the Riviere du Carbet valley, where 20-25\% of the collapsing mass is conveyed in both SP3 and SP4. Part of the mass (about 9\%) is channelized to the North-East in the Rivière du Perou valley in simulation SP4. Toward the South, in both SP3 and SP4, between 10 and $15 \%$ of the collapsed mass is conveyed 


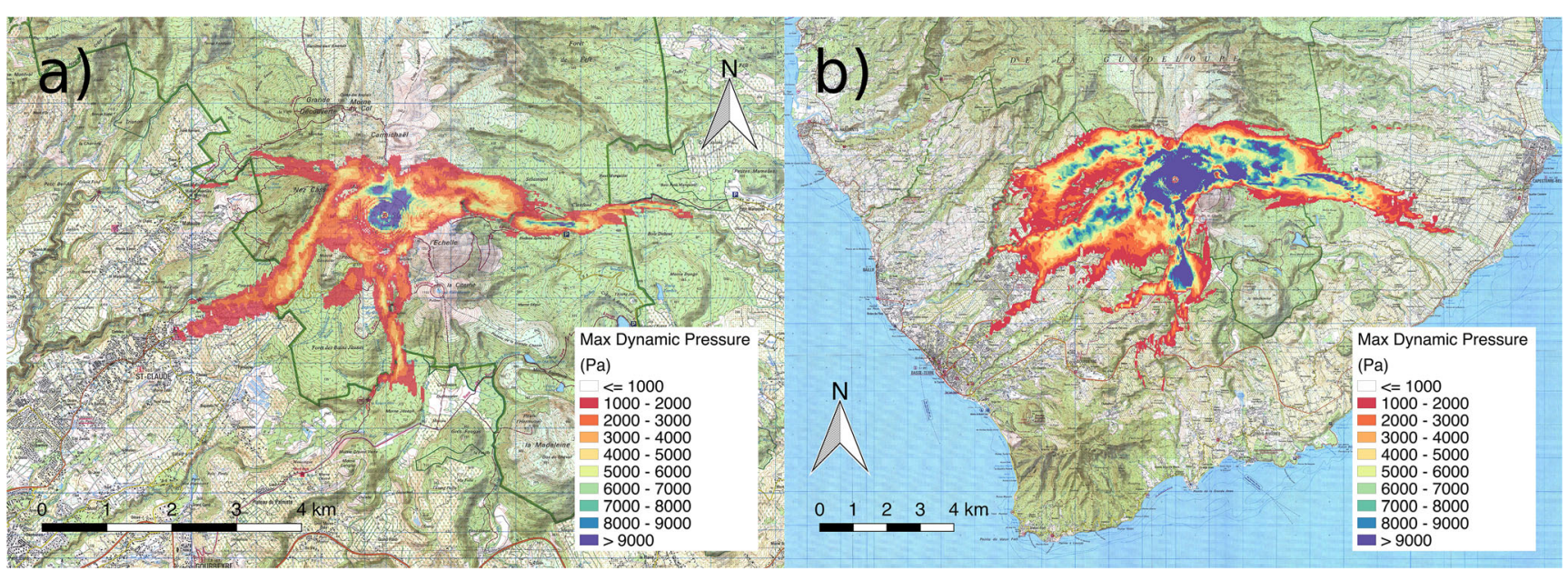

Fig. 9 Maps of maximum dynamic pressure estimated for each point in the domain for scenarios a SP3 and b SP4

along a narrow ravine through the Chute $d u$ Galion to branch downstream into two main streams, one being channelized along the Rivière $d u$ Galion valley and the other more diffused around the Morne-Joseph (Rivière de la Grande Anse; Fig. 2).

In both SP3 and SP4, most of the collapsing mass is deflected to the South-West by the Nez Cassé ridge and down the Savane à Mulets - Plateau Dimba area towards the town of Saint-Claude. In this direction, this appears to be the main "outlet" of the summit morphological structure. Pyroclastic density currents initially branch into two main valleys: the Rivière Noire (West sector) and the Rivière Dugommier (South-West sector), but they merge downstream after about $2 \mathrm{~km}$. In contrast to the other sectors, where an equilibrium is reached between sedimentation and elutriation (so that the mass ratio becomes more or less constant), the mass ratio increases down-flow in the South-West sector, denoting an accumulation of the deposited material but also reflecting the increasing contributions from the Southern and NorthWestern PDC branches which merge down-flow. The remaining collapsing mass remains within the summit area $(35 \%$ for SP3, 10\% for SP4).

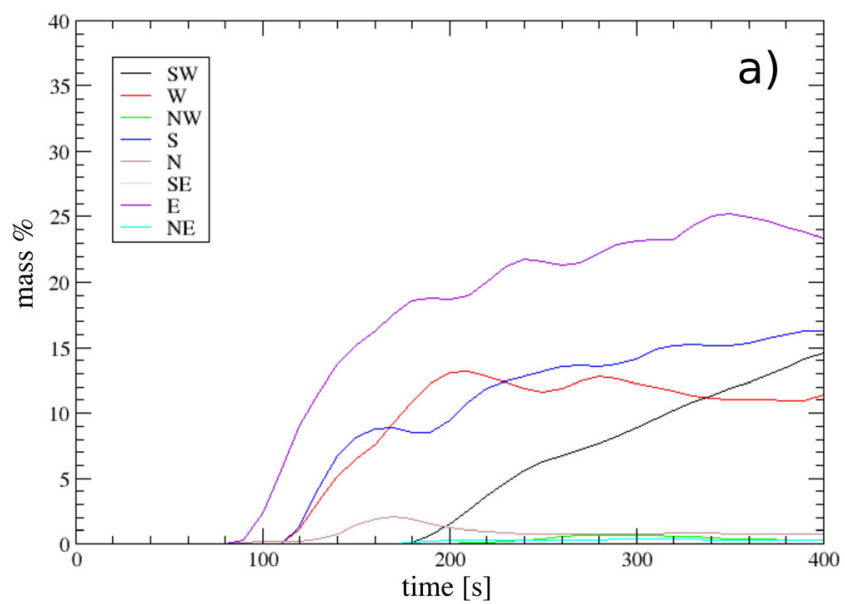

The topography of the SDG massif, the likelihood of partial edifice collapse, and the high-water content of the magma all favour an almost total collapse of the eruption column and a strong control of topography on the distribution of PDCs. These factors have been shown to be a very efficient means of enhancing the mobility of PDCs during the 2010 eruption of Merapi (Komorowski et al. 2015). At SDG, focussing of PDC material down ravines and deep canyons for several kilometres is likely to contribute to hotter than expected gas-rich PDCs, with greater potential impacts on humans and the built environment. Moreover, focussing more mass at greater distances will increase the likelihood of secondary turbulent PDCs being generated that could overtop topographic divides and barriers and invade areas not directly exposed to the channelized and concentrated parental PDCs. This has been shown to have been the case during the Soufrière Hills eruption of 1997 (Druitt et al. 2002b) and at Merapi volcano in 2010 (Komorowski et al. 2015). Deposition of PDC material in valleys will also favour the generation of

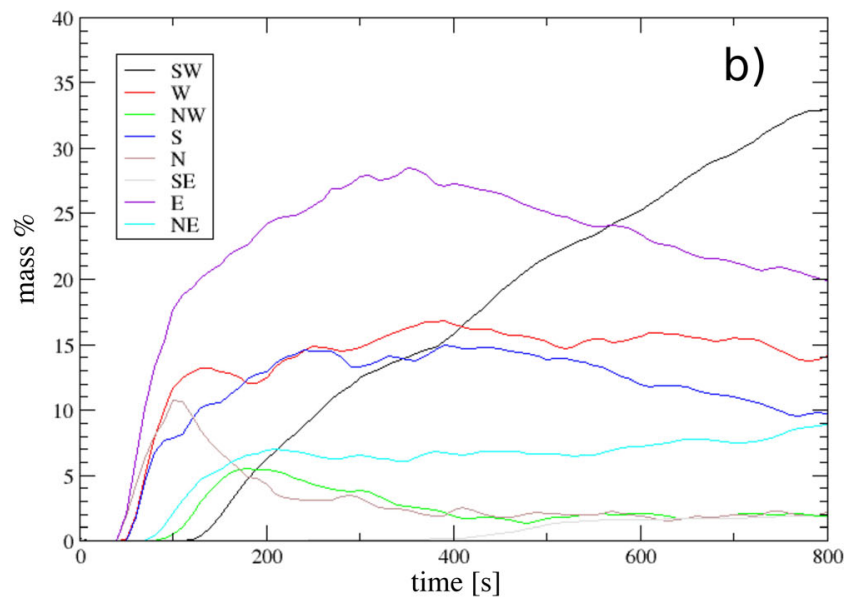

Fig. 10 Ratio of mass conveyed into valleys by PDC with respect to the collapsed total mass for simulations a SP3 and b SP4 
debris flows and lahars after the end of the eruption (cf. Scott et al. 1996). Our modelled PDCs from total column collapse scenarios are able to reach the coastline at least to the East, entering the sea close to the town of Capesterre-Belle-Eau and to the South-West in the town of Basse-Terre (the location of the Guadeloupe préfecture, i.e. the centre of decision making and governance by the authority representing the national government). Depending on the total mass and the mass flux into the sea, such PDC entry into the sea could lead to the generation of tsunamis (Begét 2000; Tinti et al. 2003; Paris 2015) that could refract along the coastline North and South from the entry point as well as propagate eastward towards the islands of Les Saintes and Marie-Galante (Fig. 2). Such cascading phenomena must be further modelled and their potential impact quantified in adequate simulations.

\section{Discussion}

Numerical results describe the spatial (in 3D) and temporal detail of formation, instability, and partial collapse of eruptive columns. For the case considered here, the percentage of collapse, at constant mass eruption rate, increases with the vent radius. Partial collapse episodes generate pyroclastic accumulation at the base of the plume which then flows away from the base as PDCs. The horseshoe-shaped collapse structure of the summit area and the incised nature of the volcano flanks then control the areal distribution of the PDCs.

\section{PDC mobility and intensity}

Simulations show that partial collapses occurring from an oscillating column intermittently generate axisymmetric spreading of PDCs across all sectors of the volcano. However, PDC intensity (i.e. their mass flow rate per unit of angle) is limited, even at a collapse rate of about 70\%. Our modelled PDCs are significantly cooled and slowed by air entrainment, gas drag, and lift-off. Such an observation is supported by numerical modelling by Trolese et al. (2019) who showed that PDC temperature is linearly correlated with the percentage of column collapse.

Our numerical simulations show that PDCs from oscillating columns are unable to significantly impact the inhabited zones around the volcano. This, however, is incompatible with the sedimentological observations of PDC deposits in the town of St. Claude and in the main drainages, at distances of 6-7 km (Boudon et al. 2008; Fig. 3). To achieve such distances, our modelling shows that a regime of full collapse (i.e. $>90 \%$ of collapse) and low fountaining would be necessary, with an increased mass flow rate of $2.8 \times 10^{7} \mathrm{~kg} / \mathrm{s}$. Pyroclastic density currents generated in a regime of full column collapse are able to reach distances of $>8 \mathrm{~km}$ from the vent in less than $15 \mathrm{~min}$, and to overtop topographic barriers that otherwise block flows. Such PDCs are able to reach distal areas while maintaining dynamic pressures of up to 3-5 $\mathrm{kPa}$ and temperatures of up to $500 \mathrm{~K}$ (or $230^{\circ} \mathrm{C}$ ) in the most onland proximal locations at distances of 5-6 km, which is well into the inhabited region.

\section{Comparison with the reference scenario}

The value of $2.8 \times 10^{7} \mathrm{~kg} / \mathrm{s}$ required to impact inhabited zones is to the upper bound of the mass flow rate for the $1530 \mathrm{CE}$ eruption at SDG. It is worth noting that reconstructions of the mass eruption rate based on an estimate of plume height do not consider that, during the collapse phase, the mass feeding the plume is significantly reduced and, thus, the maximum eruption rate is likely underestimated (potentially by a factor of 10 in the case of $90 \%$ collapse; Trolese et al. 2019). Moreover, regimes of $>90 \%$ collapse are likely favoured by potential partial edifice collapse. The partial collapse of the edifice that occurred shortly after the onset of the $1530 \mathrm{CE}$ eruption, which left a large ca. 600-800-m-wide and ca. 1.2$\mathrm{km}$-long horseshoe-shaped crater open to the South and South-West (Boudon et al. 2008; Fig. 3), is much larger than the vent radius of $104 \mathrm{~m}$ that we assumed for SP4. This greater vent diameter is therefore likely to have had a profound effect on the dynamics of the eruption column and explains why PDCs during the $1530 \mathrm{CE}$ eruption were able to overcome topographic obstacles on the Northern side of SDG and flow into the upper part of the Rivière St. Louis valley, reaching a distance of about $5-6 \mathrm{~km}$ as confirmed by field mapping (Fig. 3; Boudon et al. 2008; Komorowski et al. 2008). This is in line with observations during the 2010 eruption of Merapi, where the presence of a large $400 \times 300$-m-wide and 150-200-mdeep horseshoe-shaped crater created by the initial phases of the eruption strongly controlled the direction of full collapse of the column in the final phase of the eruption, hence favouring the excessive runout of very small-volume yet mobile pyroclastic flows that travelled about $15.5 \mathrm{~km}$ from the vent (Komorowski et al. 2013).

\section{Uncertainty on model results}

Many aspects of PDC dynamics remain difficult to investigate, because of the lack of knowledge on the constitutive properties of gas-particle mixtures and the spatial resolution of the numerical simulations. In particular, it is still challenging to describe the rheology of concentrated granular mixtures in 3D (Breard et al. 2019) and to correctly reproduce vertical stratification when the vertical grid size is comparable to or larger than the thickness of the basal layer. Our model-based estimates of PDC runout, temperature, and dynamic pressure should then be taken as relative measures and are intended as 


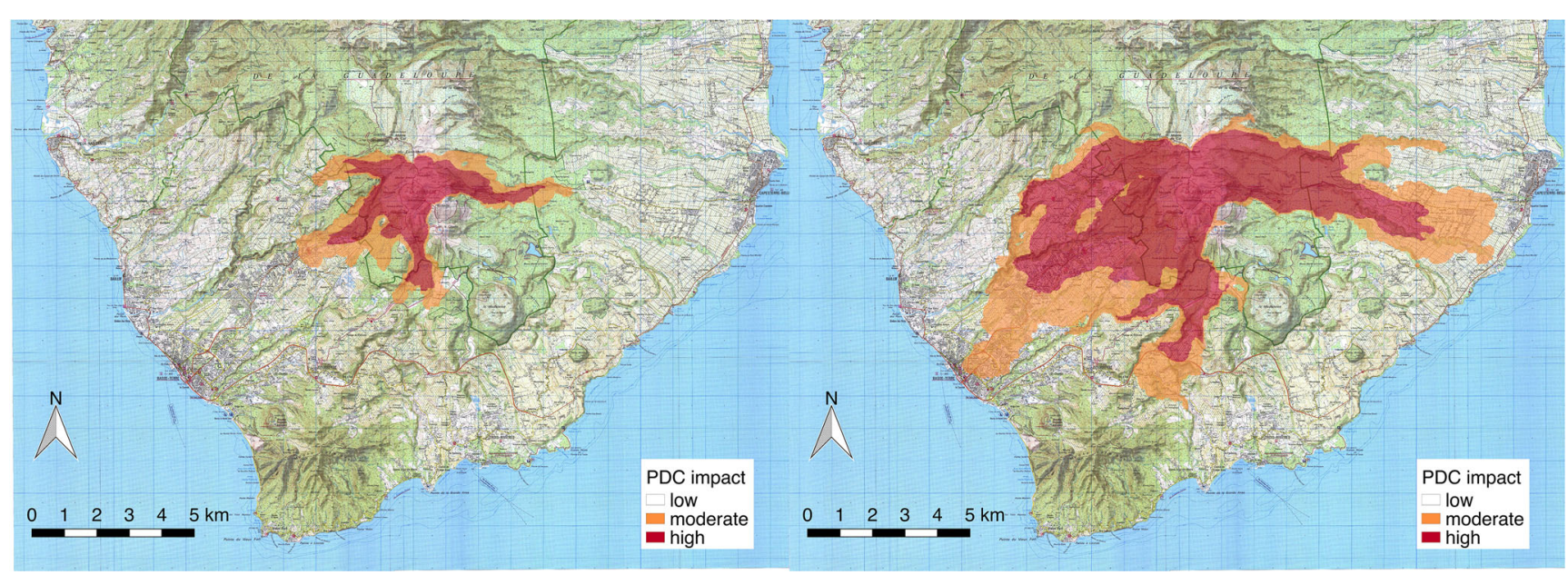

Fig. 11 Maps of PDC hazard based on temperature isolines $\left(300 \mathrm{~K}\right.$ or $27^{\circ} \mathrm{C}$, orange; $600 \mathrm{~K}$ or $327^{\circ} \mathrm{C}$, red) for two scenarios of total column collapse with a mass eruption rate of $7 \times 10^{6} \mathrm{~kg} / \mathrm{s}(\mathrm{SP} 3, \mathbf{a})$ and $3 \times 10^{7} \mathrm{~kg} / \mathrm{s}(\mathrm{SP} 4, \mathbf{b})$

average values over the first $10-20 \mathrm{~m}$ above the topography. In previous studies with comparable numerical parameters, we were able to estimate that the maximum values of dynamic pressure can be up to a factor $\sim 5$ larger as a consequence of density stratification (Esposti Ongaro et al. 2008b). Grid resolution might also affect the description of PDC deflation and pressurization at the impact zone (Valentine and Sweeney 2018). The binning of the grain size distribution can also influence the results of simulations. Although Neri et al. (2003) and Carcano et al. (2014) showed that three classes are a minimum number of bins required to achieve a satisfactory description of multiparticle dynamics, the uncertainty associated with incomplete description of the distribution is still to be evaluated (Esposti Ongaro et al. 2020). Further uncertainty in simulation results are associated with physical aspects of numerical modelling, such as sub-grid scale turbulence models and ground boundary conditions. The issue of ground boundary conditions, in particular, is strictly related to the vertical adopted numerical grid size. As already observed by Esposti Ongaro et al. (2008b, 2012), coarse grids do not allow the accurate resolution of the stratification of the flow and interaction with the lower, rough, topographic boundary. In particular, at least five cells are required to describe the flow boundary zone. This is not the case in most of our numerical simulations for the distal part of the PDC runout, where the uncertainty on numerical model results is therefore larger than in the proximal region. However, in our experience, the adopted vertical grid size is a good compromise to describe the main large-scale PDC features.

Finally, we have shown that the mass flux of pyroclastic material conveyed in PDCs is the main parameter controlling their mobility (invaded area and runout) and, consequently, their impact. We stress here that column collapse height is almost irrelevant in the determination of PDC runout and intensity, in the case of partial collapse dynamics. This observation is consistent with results of integral inertial models (Dade and Huppert 1996; Esposti Ongaro et al. 2016) but is contrary to empirical models based on the energy-line approach (e.g. Sheridan and Malin 1983; Tierz et al. 2016; Sandri et al. 2018). Although we present a relatively limited set of eruptive conditions (e.g. vent velocity, density, temperature, grain size), the same behaviour has been observed by Esposti Ongaro et al. (2008a) at Vesuvius. We therefore recommend avoidance of application of the energy-line method to stratified PDCs produced by partial column collapse, especially for hazard assessment purposes.

\section{Drawing PDC hazard maps from simulation outputs}

Drawing hazard maps for a single scenario, based on numerical model results still is a challenging task that cannot be performed in a fully automatic way. It needs, instead, some

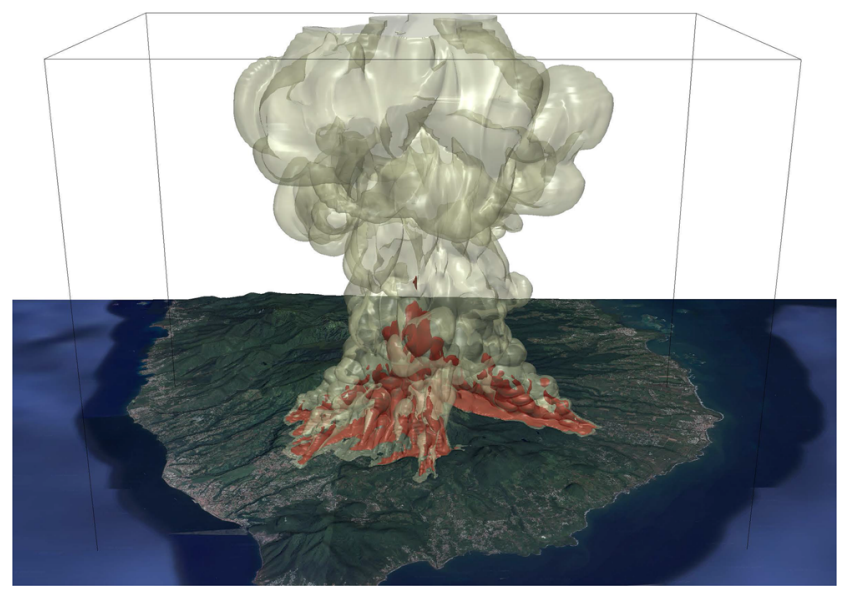

Fig. 12 Example of visualization of 3D results for communication purposes. Simulation SP4 of total $(>90 \%)$ collapse, with increased mass eruption rate of about $2.8 \times 10^{7} \mathrm{~kg} / \mathrm{s}$ (run SP4), $400 \mathrm{~s}$ after the beginning of the collapse phase. Isosurfaces of $10^{-7}$ (outer, light green) and $10^{-5}$ (inner, brown) for the volume concentration of the fine ash are superimposed on a DEM of the volcano draped with satellite images (Google (C2018 Maxar Technology) 


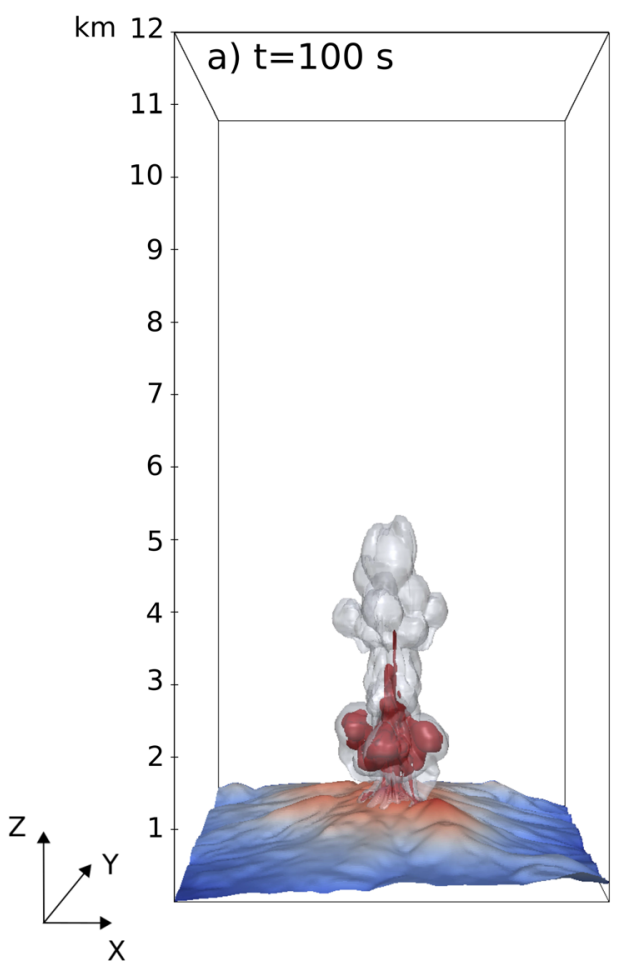

$\mathrm{km} 12$

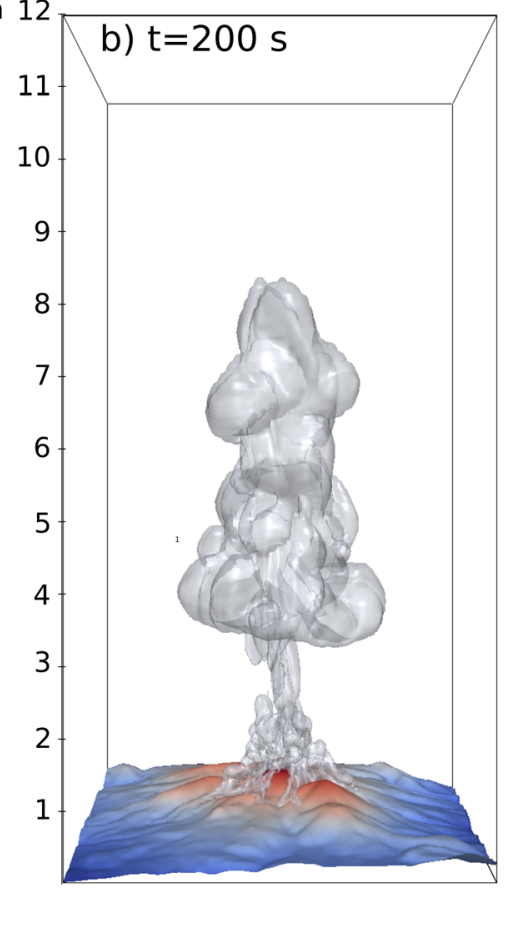

$\mathrm{km} 12$

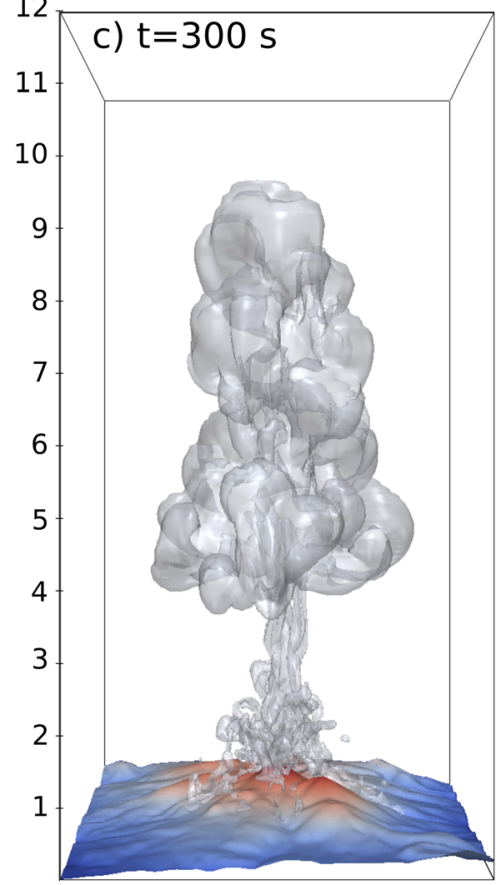

Fig. 13 Isosurface at $10^{-5}$ and $10^{-7}$ of total particle concentration in the atmosphere, at a) $100 \mathrm{~s}$, b) $200 \mathrm{~s}$ and c) $300 \mathrm{~s}$ after the beginning of the collapse phase. The flow at the conduit exit has been stopped after $20 \mathrm{~s}$,

expert judgement to account for model uncertainties (Calder et al. 2015). In particular, we have to consider the uncertainty associated with numerical errors and incomplete physical description of the phenomenon. Here, we have used different isolines of temperature to identify the areas reached by the most concentrated, basal part of the current and by the dilute ash cloud. In Fig. 11, we propose a preliminary identification of two hazard regions based on temperature isolines for both simulations SP3 and SP4. The $600 \mathrm{~K}$ isoline $\left(327^{\circ} \mathrm{C}\right)$ is considered as the region very likely invaded and highly impacted by PDCs, for the selected scenario. This is based on the following considerations:

- The isoline is stable and stationary in time (it does not further advance, once it reaches the displayed limit);

- This temperature threshold almost coincides with the limit of significant dynamic pressures (i.e. $>1 \mathrm{kPa}$ ) and of the maximum distance reached by the more concentrated (particle volume concentration of $>10^{-3}$ ) basal layer;

- Its position corresponds quite well with the limit of satisfactory vertical discretization ( $>5$ cells in the boundary layer) of the stratified PDC.

The $300 \mathrm{~K}\left(27^{\circ} \mathrm{C}\right)$ isoline, on the other hand, encloses an area susceptible to PDC invasion and moderately impacted. In this area, simulated PDCs are mostly dilute, have temperatures when the jet has reached its maximum thrust height of about $2 \mathrm{~km}$ above the vent. The $X$-axis is oriented West-East, $Y$ is oriented South-North

of between 27 and $327^{\circ} \mathrm{C}$ (still capable to cause severe injuries; Baxter et al. 2005, 2017), and have dynamic pressures of lower than $1 \mathrm{kPa}$. Here, however, the numerical uncertainty on the prediction is much larger and is more influenced by the physical approximations of the model (mostly, incomplete description) and by approximate boundary conditions at the ground surface.

Finally, the area outside of the $300 \mathrm{~K}\left(27^{\circ} \mathrm{C}\right)$ isoline should be considered as unlikely to be invaded or marginally impacted by PDCs in the selected scenario, mostly because it is sheltered by significant topographic barriers or because of the great distance between the source and the location. However, it is important to note that different vent location, geometry, and eruption conditions, as well as atmospheric conditions, could potentially change the results for such a deterministic scenario. Therefore, the zonation presented here should be considered as a preliminary product to be refined in the future.

The use of clear and quantitative hazard maps for an individual scenario, in combination with three-dimensional visualization techniques (Fig. 12), can provide the tools for a better evaluation and communication of the hazards associated with a future scenario of a subplinian eruption at SDG, and contribute to a more effective risk management strategy. To aid with this, our Electronic Supplementary Material presents video animations for the development of a subplinian column and PDCs in scenario SP4, looking from the South-West (PDC 


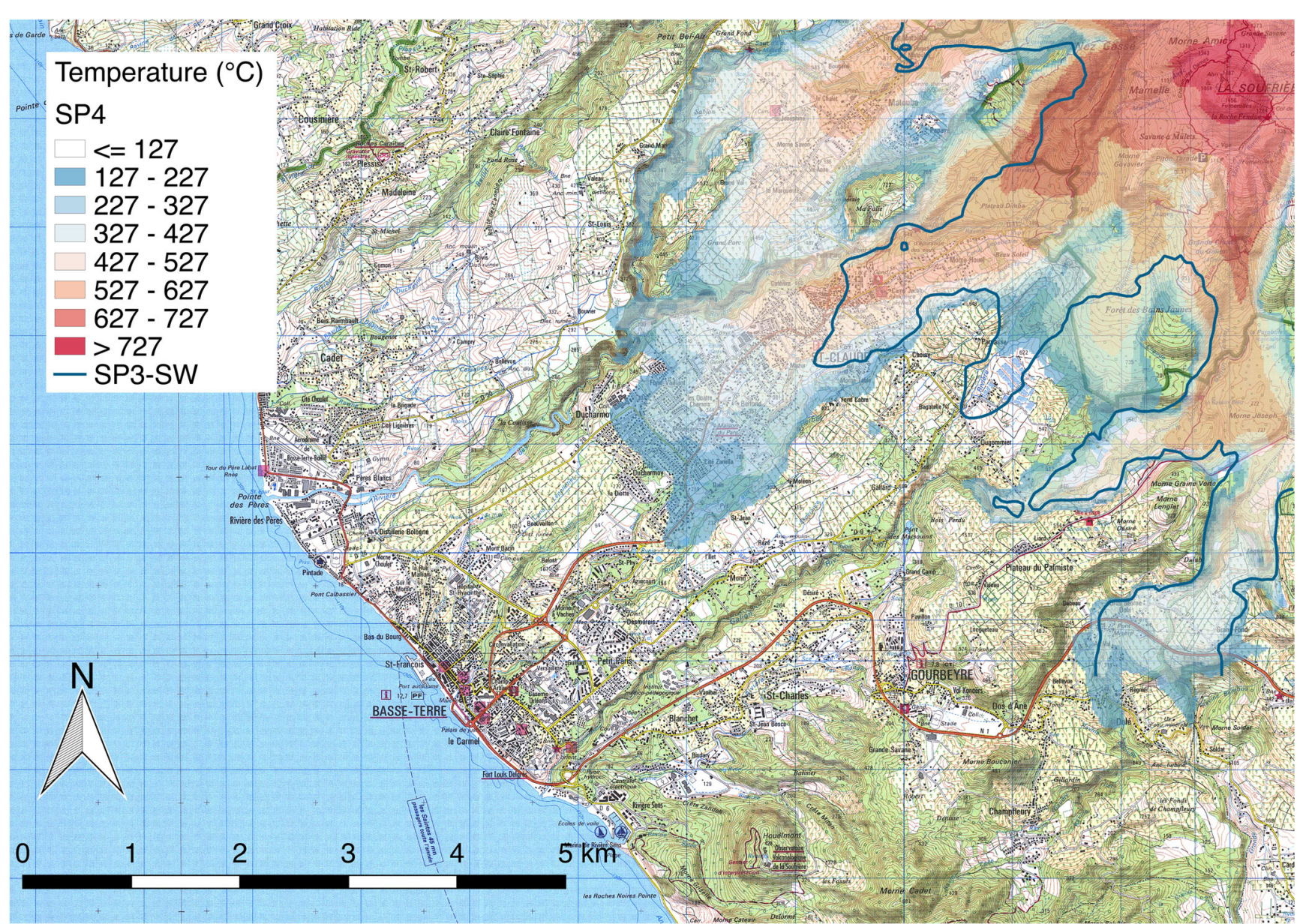

Fig. 14 Comparison between run SP4 and run SP3-SW at $t=700 \mathrm{~s}$. Mixture temperature in the first computational cell above the topography (representing the averaged value over the first $20 \mathrm{~m}$ ). The color map resulting from SP4 numerical simulation has been superimposed on the IGN map. The blue line indicates the $127^{\circ} \mathrm{C}$ temperature isoline for simulation SP3-SW branch moving towards the town of St Claude; Online Resource 1) and looking from the South (PDC branch moving towards the town of Capesterre; Online Resource 2).

The use of three-dimensional, multiphase flow models for PDC hazard assessment remains in any case challenging. The PDC hazard maps presented in Fig. 11 are limited to a single scenario (i.e. they are conditional maps), and because of the large computational cost of simulations (each lasting days to weeks on computer clusters with hundreds of CPU cores), it is difficult to assess model-related uncertainty. In addition, two key limitations in the physical/numerical description currently hinder a comprehensive simulation of PDCs. These are, first, the difficulty of describing the granular flow rheology across a broad range of particle concentrations, and second, the difficulty of achieving a vertical resolution fine enough to resolve the flow profile near the ground. The alternative use of simplified PDC models is also problematic, because the uncertainty associated to oversimplified boundary conditions (i.e. inability to describe the complexity of the explosive source), poorly constrained empirical parameters, and model approximations is even larger, although the low computational cost makes it possible to perform thousands of simulations to explore the parameter ranges in a probabilistic framework (Dalbey et al. 2008; Procter et al. 2010; Neri et al. 2015a, b; Ogburn and Calder 2017; Sandri et al. 2018; Rutarindwa et al. 2019; Lube et al. 2020). However, the exploitation of massive supercomputers and high-performance computing techniques, and the availability of open-source and community software, are driving a new step forward towards quantitative, probabilistic hazard assessment using 3D multiphase flow models. To this end, rigorous benchmarking studies are in progress to quantify the uncertainty associated with different model approximations and to provide a consensual metric for model validation (Esposti Ongaro et al. 2020).

\section{Conclusions}

We have presented the results of a numerical study aimed at assessing the factors controlling propagation, emplacement, and hazards of PDCs in a credible (cf. Baxter et al. 2008) subplinian eruption scenario at La Soufrière de Guadeloupe. 
A set of deterministic simulations were constrained using the best estimates of eruption source parameters. One of the outcomes is that, even with a narrow range of mass eruption rates, subplinian eruptions can display very different eruptive styles, with different impacts from associated PDCs. Although exploration of a more extended range of eruptive conditions and a systematic appraisal of uncertainties would be necessary to perform a complete hazard assessment study, present results allow us to draw some preliminary conclusions and to contribute to the assessment of hazard associated with a potential future reawakening of the volcano.

Low-intensity $\left(7 \times 10^{6} \mathrm{~kg} / \mathrm{s}\right)$ subplinian plumes are able to generate an oscillating column and steeply stratified PDC by a mechanism of partial collapse (50 to $70 \%$ of mass collapsing). Despite their ability to surmount proximal topographic barriers, PDC runout would be limited to the first $2-3 \mathrm{~km}$ from the vent and impacts on the inhabited region would be negligible. It is however possible (but not addressed by our modelling) that such weak plumes could be influenced by strong winds or asymmetric vent conditions, enhancing PDC runout in certain sectors.

Although partial collapse episodes are on average isotropic, the distribution of PDCs is asymmetric, due to the strong topographic control at the horseshoe-shaped collapse structure in the summit area. All simulations show that, given the present morphology of the La Soufrière de Guadeloupe volcano, most of the PDC mass will be focussed to the East-Northeast (which will take between 25 and $30 \%$ of the total mass), WestSouthwest (between 25 and 50\%), and South (10 and 15\%), with a smaller portion (less than 5\%) being emplaced in the North-Northwest sector. Between 5 and 30\% will remain within the limits of the summit area.

Fully collapsing (fountaining or boiling over) conditions (90\% of collapse) can be generated by a sudden enlargement of the vent (e.g. by a syn-eruptive partial edifice collapse such as that which occurred in the $1530 \mathrm{CE}$ eruption), with a consequent reduction of the average exit velocity (at the same mass eruption rate) and air entrainment. In such a case, PDC intensity (mass flow rate per unit of angle), mobility (including capacity of surmounting topographic barriers), and the consequent impact on surrounding populations can be strongly enhanced, potentially affecting the inhabited regions $>4 \mathrm{~km}$ from the vent.

Increase in the mass flow rate at the vent to about $2.8 \times 10^{7}$ $\mathrm{kg} / \mathrm{s}$ (or funnelling of the collapsing mass into a single sector) is sufficient to generate more mobile PDCs that are able to reach the inhabited regions about $6 \mathrm{~km}$ from the vent. This is particularly the case as PDC mass is focussed in deep valleys and canyons (> $100 \mathrm{~m}$ deep) that reach far into the inhabited areas. Pyroclastic density currents with dynamic pressures exceeding $3 \mathrm{kPa}$ and temperatures exceeding $200{ }^{\circ} \mathrm{C}$ can be expected in such cases and this is sufficient to inflict considerable damage to buildings and will be lethal to humans and animals (Baxter et al. 2005). Following Jenkins et al. (2013a), we will thus use, in a future study, the resulting spatial distribution of peak temperatures and dynamic pressures to develop a quantitative impact model for the population, infrastructure, and communication/facility networks. This will be combined with vulnerability information derived from medical analyses (cf. Baxter et al. 2017) and building engineering (cf. Jenkins et al. 2013b), and with exposure data, to quantify the risk.

Finally, by combining information on the spatial distribution of temperature and dynamic pressure with objective considerations regarding model-related uncertainty, we are able to draw preliminary PDC hazard maps for a subplinian eruptive scenario. This still requires some level of expert judgement to identify the factors that control uncertainty of numerical simulation results. In such a representation, and for the reference subplinian scenario, we identify three areas varying in susceptibility to invasion by PDC: very likely to be invaded (with dynamic pressures of $>1-10 \mathrm{kPa}$ and temperatures of $>300{ }^{\circ} \mathrm{C}$ ), susceptible to invasion (with lower dynamic pressures and temperatures), and unlikely to be invaded by PDCs. This information will need to be updated in the future by considering a broader set of eruptive conditions and uncertainties. However, we believe that, given the current increasing unrest, it can provide a useful and timely contribution to hazard assessment and crisis response in the advent of a future eruption at La Soufrière de Guadeloupe, while being a blueprint as to how to set-up hazard maps for subplinian eruption scenarios elsewhere.

Supplementary Information The online version contains supplementary material available at (https://doi.org/10.1007/s00445-020-01411-6).

Acknowledgements The authors would like to thank the management and personnel of the Observatoire Volcanologique et Sismologique de Guadeloupe (OVSG-IPGP), and the Service interministériel de défense et protection civile (SIDPC) from the Préfecture in Guadeloupe for their collaboration and logistical support. Data was obtained from Institut Géographique National (IGN). This work was supported by the Institut National des Sciences de l'Univers (INSU-CNRS), the Service National d'observation en volcanologie (SNOV, CNRS-INSU), and the CASAVA Project, 2009-2015 (ANR-09-RISK-02). We thank scientists of the CASAVA project consortium for fruitful discussions. The research leading to these results has received funding from the European Union's Horizon 2020 research and innovation programme under the ChEESE project, grant agreement No. 823844 . The scientific collaboration between INGV and IPGP was supported by the European Union's Horizon 2020 research and innovation programme, under the EUROVOLC project, grant agreement No 731070 . We finally would like to thank two anonymous reviewers, the Associate Editor C. Gregg, and the Executive Editor A. Harris for their insightful suggestions and for the time spent in their meticulous reviews during the difficult period of the COVID-19 pandemic. This study contributes to the IdEx Universite de Paris ANR-18-IDEX-0001. This is IPGP contribution No. 4171.

Funding Open access funding provided by Istituto Nazionale di Geofisica e Vulcanologia within the CRUI-CARE Agreement. 


\section{Appendix}

\section{Appendix 1. Physical and numerical model}

The PDAC (Pyroclastic Dispersal Analysis Code) model solves the coupled transport equations of mass, momentum, and enthalpy for a mixture of volcanic gas, atmospheric air, and three particle classes representative of fine to coarse ash. The Eulerian-Eulerian multiphase flow model formulation from Neri et al. (2003) has been adopted for gas and three single particulate classes, representing fine to coarse ash. For the four-phase gas-particle mixture, the following 3D transport equations for mass, momentum, and energy are solved. Gas and particle equations are coupled by the drag forces (allowing to simulate settling, sedimentation, and preferential concentration) and thermal exchange.

\section{Mass equations}

$$
\begin{gathered}
\frac{\partial\left(\alpha_{g} \rho_{g}\right)}{\partial t}+\nabla \cdot\left(\alpha_{g} \rho_{g} \boldsymbol{U}_{g}\right)=0 \\
\frac{\partial\left(\alpha_{s} \rho_{s}\right)}{\partial t}+\nabla \cdot\left(\alpha_{s} \rho_{s} \boldsymbol{U}_{s}\right)=0 ; s=1, \ldots, N
\end{gathered}
$$

\section{Momentum equations}

Because particle-particle collisions are neglected in the solid stress tensor, the solid pressure term is not included in the particle momentum equation (Model A of Gidaspow 1994).

$$
\begin{aligned}
& \frac{\partial}{\partial t}\left[\alpha_{g} \rho_{g} \boldsymbol{U}_{g}\right]+\nabla \cdot\left[\alpha_{g} \rho_{g} \boldsymbol{U}_{g} \boldsymbol{U}_{g}\right]=-\alpha_{g} \nabla P-\nabla \cdot \boldsymbol{T}_{g}+\alpha_{g} \rho_{g} \boldsymbol{g} \\
& +\sum_{s=1}^{N} D_{g s}\left(\boldsymbol{U}_{s}-\boldsymbol{U}_{g}\right) \\
& \frac{\partial}{\partial t}\left[\alpha_{s} \rho_{s} \boldsymbol{U}_{s}\right]+\nabla \cdot\left[\alpha_{s} \rho_{s} \boldsymbol{U}_{s} \boldsymbol{U}_{s}\right]=-\alpha_{s} \nabla P-\nabla \cdot \boldsymbol{T}_{s} \\
& +\alpha_{s} \rho_{s} \boldsymbol{g}-D_{g s}\left(\boldsymbol{U}_{s}-\boldsymbol{U}_{g}\right)+\sum_{p=1 p \neq s}^{N} D_{p s}\left(\boldsymbol{U}_{s}-\boldsymbol{U}_{p}\right) ; s=1, \ldots, N
\end{aligned}
$$

\section{Enthalpy equations}

The total enthalpy of the $i$ th phase is defined as the sum $h_{i}=e_{i}+\frac{P_{i}}{\rho_{i}}$, with $e_{i}$ as the specific internal energy. The work done by gravity and by the drag and viscous forces is neglected in both balances. Heat exchange between solid particles is also neglected, following Neri et al. (2003) and previous studies on analogous eruption scenarios.

$$
\begin{aligned}
& \frac{\partial}{\partial t}\left[\alpha_{g} \rho_{g} h_{g}\right]+\nabla \cdot\left[\alpha_{g} \rho_{g} h_{g} \boldsymbol{U}_{g}\right]=-\nabla \cdot\left(\alpha_{g} \boldsymbol{q}_{g}\right)-\alpha_{g}\left[\frac{\partial P_{g}}{\partial t}+\boldsymbol{U}_{g} \cdot \nabla P_{g}\right] \\
& +K_{g s}\left(T_{s}-T_{g}\right) \\
& \frac{\partial}{\partial t}\left[\alpha_{s} \rho_{s} h_{s}\right]+\nabla \cdot\left[\alpha_{s} \rho_{s} h_{s} \boldsymbol{U}_{s}\right]=-\nabla \cdot\left(\alpha_{s} \boldsymbol{q}_{s}\right)+K_{g s}\left(T_{g}-T_{s}\right) ; s \\
& =1, \ldots, N
\end{aligned}
$$

\section{Closure equations}

The gas and solid phases are treated as interpenetrating continua. Their volume fractions obey the closure equation:
$\alpha_{g}+\sum_{s=1}^{N} \alpha_{s}=1$

The thermal equation of state of the gas phase is that of perfect gases. Particle density is constant.

$\rho_{g}=\rho_{g}\left(P, T_{g}\right) ; \rho_{s}=$ constant

For both the gas and particles, the stress tensor is written in a Newtonian form:

$$
\begin{gathered}
\boldsymbol{T}_{i}=\alpha_{i} \rho_{i}\left[2 \nu_{\mathrm{eff}} \boldsymbol{S}_{i}+\lambda_{i}\left(\nabla \cdot \boldsymbol{U}_{i}\right) \boldsymbol{I}\right] \\
\boldsymbol{S}_{i}=\frac{1}{2}\left(\nabla \boldsymbol{U}_{i}+\nabla \boldsymbol{U}_{i}^{T}\right)-\frac{1}{3}\left(\nabla \cdot \boldsymbol{U}_{i}\right) \boldsymbol{I}
\end{gathered}
$$

where the subscript $(i)$ indicates either gas or particles and $\nu_{\text {eff }}$ is the effective viscosity coefficient $\left(\nu_{\text {eff }}=\nu+\right.$ $\left.\nu_{\text {turb }}\right)$ and is the sum of the molecular/granular viscosity $\nu$ and the turbulent (sub-grid) turbulent coefficient. For the gas, the molecular viscosity depends on temperature and is equal to $1.84 \times 10^{-5}$ for gas at ambient temperature; the turbulent term is defined by Smagorinsky's Large-Eddy Simulation model (Neri et al. 2003). For particles, the granular viscosity is proportional to particle concentration $\nu_{s}=c_{s} \alpha_{s}$ (Miller and Gidaspow 1992), whereas the turbulent-collisional turbulent stress is neglected.

The heat flux is expressed through the Fourier law, for both gas and particles:

$\boldsymbol{q}_{i}=-\rho_{i}\left(D_{i}+\frac{\nu_{\text {turb }}}{P r}\right) C_{P, i} \nabla T_{i}$

where Pr is the turbulent Prandtl number, set equal to 0.7 for gas and 0 for particles.

Finally, the gas-particle drag coefficient $D_{g s}$ is expressed by the Ergun-Wen-Yu law, whereas the gasparticle heat transfer coefficient $K_{h t}$ is expressed by the Ranz-Marshall law. We refer to Neri et al. (2003) for model details.

Initial conditions represent a standard, stratified dry atmosphere. Free inflow/outflow conditions are imposed at the top, and lateral boundaries, no-slip, and zero gradient conditions are imposed at the ground. Inlet conditions are imposed on a circular vent, where all fluid fields are imposed: the volume fraction, velocity, and temperature of each particle class, and the pressure, velocity, and temperature of the gas, plus the mass fraction of water vapour. The fields are corrected to account for the correct mass flow rate when the circular vent is discretized on a Cartesian mesh.

Details on the numerical solution algorithm are given by Esposti Ongaro et al. (2007). Table 3 reports the complete list of performed numerical sensitivity tests. 
Table 3 List of performed numerical simulations, with different numerical mesh resolutions. Symbol (§) indicates the simulations described in the paper. Symbol (*) indicates that the same simulations have been repeated with/without immersed boundary conditions (de' Michieli Vitturi et al. 2007). Symbol (†) indicates that the same simulation has been repeated with modified ground boundary condition (a leaky boundary, as in Dufek and Bergantz 2007b)
Table 4 List of mathematical symbols (bold indicates vectors or tensors)

\begin{tabular}{lllll}
\hline $\begin{array}{l}\text { Numerical } \\
\text { parameters }\end{array}$ & Domain $\left[\mathrm{km}^{3}\right]$ & $\begin{array}{l}\text { Number of cells } \\
(\mathrm{nx} \times \mathrm{ny} \times \mathrm{nz})\end{array}$ & $\begin{array}{l}\text { Minimum- } \\
\text { Maximum } \\
\text { grid size dx-dy }[\mathrm{m}]\end{array}$ & $\begin{array}{l}\text { Minimum- } \\
\text { Maximum } \\
\text { grid size dz }[\mathrm{m}]\end{array}$ \\
\hline SP1 & $6 \times 6 \times 12\left(\S, \dagger^{*}\right)$ & $200 \times 200 \times 200$ & $10-50$ & $10-200$ \\
& $6 \times 6 \times 8$ & $200 \times 200 \times 350$ & $10-50$ & $5-100$ \\
SP2 & $11 \times 11 \times 8$ & $200 \times 200 \times 250$ & $10-100$ & $10-100$ \\
& $6 \times 6 \times 12(\dagger)$ & $200 \times 200 \times 200$ & $10-50$ & $10-200$ \\
& $11 \times 11 \times 8$ & $100 \times 100 \times 150$ & $20-250$ & $10-200$ \\
SP3 & $11 \times 11 \times 8(\S)$ & $200 \times 200 \times 150$ & $10-50$ & $10-200$ \\
SP3-SW & $6 \times 6 \times 12$ & $200 \times 200 \times 200$ & $10-50$ & $10-200$ \\
& $20 \times 12 \times 8(\S)$ & $400 \times 200 \times 150$ & $20-100$ & $20-200$ \\
SP3-SE & $6 \times 6 \times 8$ & $200 \times 200 \times 200$ & $10-50$ & $10-100$ \\
SP4 & $8 \times 11 \times 8$ & $100 \times 100 \times 150$ & $20-100$ & $20-100$ \\
& $20 \times 12 \times 15(\S)$ & $400 \times 200 \times 200$ & $20-100$ & $20-100$ \\
& & & & $20-200$ \\
\hline
\end{tabular}

\begin{tabular}{lll}
\hline Symbol & Definition & Units \\
\hline $\boldsymbol{\alpha}$ & Phase volume fraction & \\
$\boldsymbol{\rho}$ & Density & $\mathrm{kg} \mathrm{m}^{-3}$ \\
$\boldsymbol{U}$ & Velocity (vector) & $\mathrm{m} \mathrm{s}^{-1}$ \\
$\mathrm{P}$ & Pressure & $\mathrm{kg} \mathrm{m}^{-1} \mathrm{~s}^{-2}$ \\
$\mathrm{~T}$ & Temperature & $\mathrm{K}^{-2}$ \\
$\mathrm{~h}$ & Specific enthalpy & $\mathrm{m}^{2} \mathrm{~s}^{-2}$ \\
$\mathrm{D}_{g s}$ & Gas-particle drag coefficient & $\mathrm{kg} \mathrm{m}^{-3} \mathrm{~s}^{-1}$ \\
$\mathrm{D}_{p s}$ & Particle-particle drag coefficient & $\mathrm{kg} \mathrm{m}^{-3} \mathrm{~s}^{-1}$ \\
$\mathrm{~K}_{g s}$ & Gas-particle heat exchange coefficient & $\mathrm{m}^{2} \mathrm{~s}^{-3} \mathrm{~K}^{-1}$ \\
$\boldsymbol{T}$ & Deviatoric stress tensor & $\mathrm{kg} \mathrm{m}^{-1} \mathrm{~s}^{-2}$ \\
$\boldsymbol{S}$ & Deviatoric strain & $\mathrm{s}^{-1}$ \\
$\boldsymbol{I}$ & Identity tensor & \\
$\boldsymbol{q}$ & Heat flux & $\mathrm{kg} \mathrm{s}^{-3}$ \\
$\mathrm{D}_{i}$ & Diffusion coefficient & \\
$\nu, \nu_{t u r b}, \nu_{e f f}$ & Molecular, turbulent, and effective kinematic viscosity & $\mathrm{m}^{2} \mathrm{~s}^{-1}$ \\
$\lambda$ & Second molecular viscosity & $\mathrm{m}^{2} \mathrm{~s}^{-1}$ \\
$\mathrm{Pr}$ & Prandtl number & \\
$C_{P, i}$ & Specific heat at constant Pressure & $\mathrm{m}^{2} \mathrm{~s}^{-2} \mathrm{~K}^{-1}$ \\
$\boldsymbol{g}$ & Gravity acceleration & $\mathrm{m} \mathrm{s}^{-2}$ \\
$g, s, p$ & Subscripts for gas and solid phases & \\
$N$ & Total number of gas + solid phases & \\
\hline & & \\
\hline
\end{tabular}

\section{Appendix 2. Single collapse pulse}

To better understand the mechanism of PDC formation by partial column collapse (50\% of mass collapsing), we have simulated a single, impulsive collapse scenario, by stopping the flow feeding at the volcanic vent at the time where the column had reached its maximum thrust height (at $t=20 \mathrm{~s}$ ).
In this way, we avoided the complexity associated to the superposition of multiple collapse events in the caldera and, consequently, reduce the problem of the accumulation of pyroclasts in the basal flow to form a dense basal layer.

At $20 \mathrm{~s}$, the total erupted mass was equal to about $1.4 \times 10^{8}$ $\mathrm{kg}$. The distribution of the total particle volumetric fraction in the atmosphere is represented in Fig. 13 by the two isosurfaces 
at $10^{-4}$ and $10^{-6}$ (Fig. 4 presents the same figure but for a continuous feeding). The invaded area is reduced, with respect to the case where the column is continuously fed. This observation confirms that accumulation of pyroclasts in the proximal area is a key element to understand PDC mobility and to correctly predict their interaction with the volcano morphology (including channelization effects) and their final runout.

\section{Appendix 3. Anisotropic PDC focussing in the South-West sector}

Simulations were performed towards the most inhabited region, to the South-Western sector of the volcano, where most of the collapsing mass is driven by the proximal caldera morphology (Fig. 14). We imposed the same mass eruption rate of scenario SP3 on one quarter of the domain (i.e. focussing in a $90^{\circ}$ sector), which is equivalent to a mass eruption rate 4 times larger (i.e. $2.8 \times 10^{7} \mathrm{~kg} / \mathrm{s}$ ), with a consequently larger impact. Because the mass flow rate per unit of angle is the same as the SP4 case, the resulting PDC runout and intensity in the inhabited region of St. Claude are comparable. However, simulation SP4 has a much longer runout to the South-West, as a result of anisotropic mass distribution. As visible in Fig. 9b, the percentage of mass conveyed towards South-West in run SP4 is larger than $35 \%$ of the total collapsing mass, which, alone, is larger than the total mass flow rate in run SP3-SW.

Open Access This article is licensed under a Creative Commons Attribution 4.0 International License, which permits use, sharing, adaptation, distribution and reproduction in any medium or format, as long as you give appropriate credit to the original author(s) and the source, provide a link to the Creative Commons licence, and indicate if changes were made. The images or other third party material in this article are included in the article's Creative Commons licence, unless indicated otherwise in a credit line to the material. If material is not included in the article's Creative Commons licence and your intended use is not permitted by statutory regulation or exceeds the permitted use, you will need to obtain permission directly from the copyright holder. To view a copy of this licence, visit http://creativecommons.org/licenses/by/4.0/.

\section{References}

Baxter PJ, Boyle R, Cole P, Neri A, Spence R, Zuccaro G (2005) The impacts of pyroclastic surges on buildings at the eruption of the Soufrière Hills volcano, Montserrat. Bull Volcanol 67:292-313. https://doi.org/10.1007/s00445-004-0365-7

Baxter PJ, Aspinall WP, Neri A, Zuccaro G, Spence RJS, Cioni R, Woo G (2008) Emergency planning and mitigation at Vesuvius: a new evidence-based approach. J Volcanol Geotherm Res 178:454-473. https://doi.org/10.1016/j.jvolgeores.2008.08.015

Baxter PJ, Jenkins S, Seswandhana R, Komorowski JC, Dunn K, Purser D, Voight B, Shelley I (2017) Human survival in volcanic eruptions: thermal injuries in pyroclastic surges, their causes, prognosis and emergency management. Burns 43:1-19. https://doi.org/10.1016/j. burns.2017.01.025

Begét JE (2000) Volcanic tsunamis. In: Sigurdsson H, Houghton B, Mc Nutt SR, Rymer H, Stix J (eds) Encyclopedia of volcanoes. Academic Press, New York, pp 1005-1013

Benage MC, Dufek J, Mothes PA (2016) Quantifying entrainment in pyroclastic density currents from the Tungurahua eruption, Ecuador: integrating field proxies with numerical simulations. Geophys Res Lett. https://doi.org/10.1002/(ISSN)1944-8007

Bernard J, Kelfoun K, Le Pennec J-L, Vallejo Vargas S (2014) Pyroclastic flow erosion and bulking processes: comparing fieldbased vs. modeling results at Tungurahua volcano, Ecuador. Bull Volcanol 76:151-116. https://doi.org/10.1007/s00445-014-0858-y

Biass S, Bonadonna C, Houghton BF (2019) A step-by-step evaluation of empirical methods to quantify eruption source parameters from tephra-fall deposits. J Appl Volcanol 8:46-16. https://doi.org/10. 1186/s13617-018-0081-1

Bonadonna C, Costa A (2012) Estimating the volume of tephra deposits: a new simple strategy. Geology 40:415-418. https://doi.org/10. 1130/G32769.1

Boudon G, Dagain J, Semet MP, Westercamp D (1988) Carte géologique à 1/ 20000e du Massif volcanique de la Soufriére, BRGM-CNRSDRM-IPGP, Editions BRGM, Orléans (1 sheet) et Notice explicative de la carte géologique à $1 / 20000$ e du Massif volcanique de la Soufriére - Carte Géologique, BRGM-CNRS-DRM-IPGP, Editions BRGM, Orléans, pp. 1-43

Boudon G, Le Friant A, Komorowski J-C et al (2007) Volcano flank instability in the Lesser Antilles Arc: diversity of scale, processes, and temporal recurrence. J Geophys Res, SE 112:B08205. https:// doi.org/10.1029/2006JB004674

Boudon G, Komorowski J-C, Villemant B, Semet MP (2008) A new scenario for the last magmatic eruption of La Soufrière of Guadeloupe (Lesser Antilles) in 1530 A.D. Evidence from stratigraphy radiocarbon dating and magmatic evolution of erupted products. J Volcanol Geotherm Res 178:474-490. https://doi.org/10. 1016/j.jvolgeores.2008.03.006

Brand BD, Gravley DM, Clarke AB, Lindsay JM, Bloomberg SH, Agustin-Flores J, Németh K (2014) A combined field and numerical approach to understanding dilute pyroclastic density current dynamics and hazard potential: Auckland Volcanic Field, New Zealand. J Volcanol Geotherm Res 276:215-232. https://doi.org/10.1016/j. jvolgeores.2014.01.008

Branney MJ, Kokelaar BP (2002) Pyroclastic density currents and the sedimentation of ignimbrites. Geological Society of London, London. https://doi.org/10.1144/GSL.MEM.2003.027

Breard ECP, Lube G (2017) Inside pyroclastic density currents uncovering the enigmatic flow structure and transport behaviour in large-scale experiments. Earth Planet Sci Lett 458:22-36. https:// doi.org/10.1016/j.eps1.2016.10.016

Breard ECP, Dufek J, Roche O (2019) Continuum modelling of pressurebalanced and fluidized granular flows in 2D: comparison with glass bead experiments and implications for concentrated pyroclastic currents. J Geophys Res, SE 2018JB016874-27. https://doi.org/10. 1029/2018JB016874

Brothelande E, Finizola A, Peltier A, Delcher E, Komorowski JC, di Gangi F, Borgogno G, Passarella M, Trovato C, Legendre Y (2014) Fluid circulation pattern inside La Soufrière volcano (Guadeloupe) inferred from combined electrical resistivity tomography, self-potential, soil temperature and diffuse degassing measurements. J Volcanol Geotherm Res 288:105-122. https://doi.org/10. 1016/j.jvolgeores.2014.10.007

Burden RE, Phillips JC, Hincks TK (2011) Estimating volcanic plume heights from depositional clast size. J Geophys Res 116. https://doi. org/10.1029/2011JB008548 
Bursik MI, Woods AW (1996) The dynamics and thermodynamics of large ash flows. Bull Volcanol 58:175-193. https://doi.org/10.1007/ s004450050134

Calder E, Wagner K, Ogburn SE (2015) Volcanic hazard maps. In: Loughlin SC, Sparks S, Brown SK et al (eds) Global Volcanic Hazards and Risk. Cambridge University Press, Cambridge, pp 335-342. https://doi.org/10.1017/CBO9781316276273.022

Capra L, Macías JL, Cortés A, Dávila N, Saucedo R, Osorio-Ocampo S, Arce JL, Gavilanes-Ruiz JC, Corona-Chávez P, García-Sánchez L, Sosa-Ceballos G, Vázquez R (2016) Preliminary report on the July 10-11, 2015 eruption at Volcán de Colima: pyroclastic density currents with exceptional runouts and volume. J Volcanol Geotherm Res 310:39-49. https://doi.org/10.1016/j.jvolgeores.2015.11.022

Carazzo G, Kaminski E, Tait S (2010) The rise and fall of turbulent fountains: a new model for improved quantitative predictions. J Fluid Mech 657:265-284. https://doi.org/10.1017/ S002211201000145X

Carcano S, Bonaventura L, Esposti Ongaro T, Neri A (2013) A semiimplicit, second-order-accurate numerical model for multiphase underexpanded volcanic jets. Geosci Model Dev 6:1905-1924. https://doi.org/10.5194/gmd-6-1905-2013

Carcano S, Esposti Ongaro T, Bonaventura L, Neri A (2014) Influence of grain-size distribution on the dynamics of underexpanded volcanic jets. J Volcanol Geotherm Res 285:60-80. https://doi.org/10.1016/j. jvolgeores.2014.08.003

Carlut J, Quidelleur X, Courtillot V, Boudon G (2000) Paleomagnetic directions and K/Ar dating of 0 to 1 Ma lava flows from La Guadeloupe Island (French West Indies): implications for timeaveraged field models. J Geophys Res, SE 105:835-849. https:// doi.org/10.1029/1999JB900238

Cerminara M, Esposti Ongaro T, Valade S, Harris AJL (2015) Volcanic plume vent conditions retrieved from infrared images: a forward and inverse modeling approach. J Volcanol Geotherm Res:1-19. https:// doi.org/10.1016/j.jvolgeores.2014.12.015

Cioni R, Marianelli P, Santacroce R, Sbrana A (2002) Plinian and subPlinian eruptions. In Sigurdsson $\mathrm{H}$ et al (eds) Encyclopedia of Volcanoes, Academic Press, pp 477-494

Costa A, Suzuki YJ, Cerminara M, Devenish BJ, Ongaro TE, Herzog M, van Eaton AR, Denby LC, Bursik M, de' Michieli Vitturi M, Engwell S, Neri A, Barsotti S, Folch A, Macedonio G, Girault F, Carazzo G, Tait S, Kaminski E, Mastin LG, Woodhouse MJ, Phillips JC, Hogg AJ, Degruyter W, Bonadonna C (2016) Results of the eruptive column model inter-comparison study. J Volcanol Geotherm Res 326:2-25. https://doi.org/10.1016/j.jvolgeores.2016. 01.017

Dade WB, Huppert HE (1996) Emplacement of the Taupo ignimbrite by a dilute turbulent flow. Nature 381:509-512. https://doi.org/10. $1038 / 381509 \mathrm{a} 0$

Dalbey K, Patra AK, Pitman EB, Bursik MI, Sheridan MF (2008) Input uncertainty propagation methods and hazard mapping of geophysical mass flows. J Geophys Res 113:B05203-B05216. https://doi. org/10.1029/2006JB004471

de' Michieli Vitturi M, Esposti Ongaro T, Neri A et al (2007) An immersed boundary method for compressible multiphase flows: application to the dynamics of pyroclastic density currents. Comput Geosci 11:183-198. https://doi.org/10.1007/s10596-007-9047-9

de' Michieli Vitturi M, Esposti Ongaro T, Lari G, Aravena A (2019) IMEX SfloW2D 1.0: a depth-averaged numerical flow model for pyroclastic avalanches. Geosci Model Dev 12:581-595. https://doi. org/10.5194/gmd-12-581-2019

Di Muro A, Neri A, Rosi M (2004) Contemporaneous convective and collapsing eruptive dynamics: The transitional regime of explosive eruptions. Geophys Res Lett 31:L10607-L10604. https://doi.org/ 10.1029/2004GL019709
Doyle EE, Hogg AJ, Mader HM, Sparks RSJ (2008) Modeling dense pyroclastic basal flows from collapsing columns. Geophys Res Lett 35:L04305-L04305. https://doi.org/10.1029/2007GL032585

Doyle EE, Hogg AJ, Mader HM, Sparks RSJ (2010) A two-layer model for the evolution and propagation of dense and dilute regions of pyroclastic currents. J Volcanol Geotherm Res 190:365-378. https://doi.org/10.1016/j.jvolgeores.2009.12.004

Druitt TH (1998) Pyroclastic density currents. In: Gilbert JS, Sparks RSJ (eds) The physics of explosive volcanic eruptions. Geological Society, London, Special Publications, 145, pp 145-182

Druitt TH, Young SR, Baptie B, Bonadonna C, Calder ES, Clarke AB, Ryan G (2002a) Episodes of cyclic Vulcanian explosive activity with fountain collapse at Soufrière Hills Volcano, Montserrat. In: Druitt TH, Kokelaar BP (eds), The eruption of Soufrière Hills volcano, Montserrat, from 1995 to 1999. Mem Geol Soc London 21: 281-306

Druitt TH, Calder ES, Cole PD, Hoblitt RP, Loughlin SC, Norton GE, Ritchie LJ, Sparks RSJ, Voight B (2002b) Small-volume, highly mobile pyroclastic flows formed by rapid sedimentation from pyroclastic surges at Soufrière Hills volcano, Montserrat: an important volcanic hazard. In: Druitt TH, Kokelaar BP (eds), The eruption of Soufrière Hills volcano, Montserrat, from 1995 to 1999. Mem Geol Soc London 21:263-280

Dufek J (2015) The fluid mechanics of pyroclastic density currents. Annu Rev Fluid Mech 48(1):459-485. https://doi.org/10.1146/annurevfluid-122414-034252

Dufek J, Bergantz GW (2007a) Dynamics and deposits generated by the Kos Plateau Tuff eruption: Controls of basal particle loss on pyroclastic flow transport. Geochem Geophys Geosyst 8:8. https://doi. org/10.1029/2007GC001741

Dufek J, Bergantz GW (2007b) Suspended load and bed-load transport of particle-laden gravity currents: the role of particle-bed interaction. Theor Comput Fluid Dyn 21:119-145. https://doi.org/10.1007/ s00162-007-0041-6

Esposti Ongaro T, Cerminara M (2016) Non-equilibrium processes in ash-laden volcanic plumes: new insights from 3D multiphase flow simulations. J Volcanol Geotherm Res 326:127-142. https://doi.org/ 10.1016/j.jvolgeores.2016.04.004

Esposti Ongaro T, Neri A, Todesco M, Macedonio G (2002) Pyroclastic flow hazard assessment at Vesuvius (Italy) by using numerical modeling. II. Analysis of flow variables. Bull Volcanol 64:178 191. https://doi.org/10.1007/s00445-001-0190-1

Esposti Ongaro T, Cavazzoni C, Erbacci G, Neri A, Salvetti MV (2007) A parallel multiphase flow code for the 3D simulation of explosive volcanic eruptions. Parallel Comput 33:541-560. https://doi.org/10. 1016/j.parco.2007.04.003

Esposti Ongaro T, Neri A, Menconi G, de'Michieli Vitturi M, Marianelli P, Cavazzoni C, Erbacci G, Baxter PJ (2008a) Transient 3D numerical simulations of column collapse and pyroclastic density current scenarios at Vesuvius. J Volcanol Geotherm Res 178:378-396. https://doi.org/10.1016/j.jvolgeores.2008.06.036

Esposti Ongaro T, Clarke AB, Neri A, Voight B, Widiwijayanti C (2008b) Fluid dynamics of the 1997 Boxing Day volcanic blast on Montserrat, West Indies. J Geophys Res 113:B03211-B03229. https://doi.org/10.1029/2006JB004898

Esposti Ongaro T, Neri A, Todesco M (2010) 3D numerical simulation of pyroclastic density current propagation in a complex topographic environment. American Geophysical Union, Fall Meeting 2010, Abstract id. V11E-02

Esposti Ongaro T, Clarke AB, Voight B, Neri A, Widiwijayanti C (2012) Multiphase flow dynamics of pyroclastic density currents during the May 18, 1980 lateral blast of Mount St. Helens. J Geophys Res 117: B06208-B06222. https://doi.org/10.1029/2011JB009081

Esposti Ongaro T, Orsucci S, Cornolti F (2016) A fast, calibrated model for pyroclastic density currents kinematics and hazard. J Volcanol 
Geotherm Res 327:257-272. https://doi.org/10.1016/j.jvolgeores. 2016.08.002

Esposti Ongaro T, Cerminara M, Charbonnier SJ, Lube G, Valentine GA (2020) A framework for validation and benchmarking of pyroclastic current models. Bull Volcanol 82:51-17. https://doi.org/10.1007/ s00445-020-01388-2

Feuillard M, Allégre CJ, Brandéis G, Gaulon R, Le Mouël JL, Mercier JC, Pozzi JP, Semet MP (1983) The 1975-1977 crisis of La Soufriére de Guadeloupe (F.W.I): a still-born magmatic eruption. J Volcanol Geotherm Res 16:317-334

Fisher RV (1995) Decoupling of pyroclastic currents: hazards assessments. J Volcanol Geotherm Res 66:257-263. https://doi.org/10. 1016/0377-0273(94)00075-r

Fisher RV, Heiken G (1982) Mt. Pelée, Martinique: May 8 and 20, 1902, pyroclastic flows and surges. J Volcanol Geotherm Res 13:339-371. https://doi.org/10.1016/0377-0273(82)90056-7

Fisher RV, Orsi G, Ort M, Heiken G (1993) Mobility of a large-volume pyroclastic flow - emplacement of the Campanian ignimbrite, Italy. J Volcanol Geotherm Res 56:205-220. https://doi.org/10.1016/ 0377-0273(93)90017-1

Fujii T, Nakada S (1999) The 15 September 1991 pyroclastic flows at Unzen Volcano (Japan), a flow model for associated ash-cloud surges. J Volcanol Geotherm Res 89:159-172

Gidaspow D (1994) Multiphase flow and fluidization: continuum and kinetic theory descriptions. Academic Press

Giordano G, Doronzo DM (2017) Sedimentation and mobility of PDCs: a reappraisal of ignimbrites' aspect ratio. Sci Rep 7:286-287. https:// doi.org/10.1038/s41598-017-04880-6

Gueugneau V, Kelfoun K, Druitt T (2019) Investigation of surge-derived pyroclastic flow formation by numerical modelling of the 25 June 1997 dome collapse at Soufrière Hills Volcano, Montserrat. Bull Volcanol 81:25-14. https://doi.org/10.1007/s00445-0191284-y

Gurioli L, Pareschi MT, Zanella E, Lanza R, Deluca E, Bisson M (2005) Interaction of pyroclastic density currents with human settlements: evidence from ancient Pompeii. Geol 33:441-444. https://doi.org/ 10.1130/G21294.1

Hincks TK, Komorowski J-C, Sparks SR (2014) Retrospective analysis of uncertain eruption precursors at La Soufrière volcano, Guadeloupe, 1975-77: volcanic hazard assessment using a Bayesian Belief Network approach. J Appl Volcanol 3:3. https:// doi.org/10.1186/2191-5040-3-3

Ishimine Y (2006) Sensitivity of the dynamics of volcanic eruption columns to their shape. Bull Volcanol 68:516-537. https://doi.org/10. 1007/s00445-005-0027-4

Jenkins SF, Spence RJS, Fonseca JFBD, Solidum RU, Wilson TM (2010) Volcanic risk assessment: quantifying physical vulnerability in the built environment. J Volcanol Geotherm Res 276:105-120. https://doi.org/10.1016/j.jvolgeores.2014.03.002

Jenkins S, Komorowski J-C, Baxter PJ, Spence R, Picquout A, Lavigne F, Surono (2013a) The Merapi 2010 eruption: an interdisciplinary impact assessment methodology for studying pyroclastic density current dynamics. J Volcanol Geotherm Res 261:316-329. https:// doi.org/10.1016/j.jvolgeores.2013.02.012

Jenkins S, Spence R, Baxter P, Komorowski J-C, Barsotti S, Esposti Ongaro T, Neri A (2013b) Modelling of disaster risk scenarios at La Soufrière, Guadeloupe. Geophys Res Abstr 15:EGU2013EG10852

Kaminski E, Jaupart C (1998) The size distribution of pyroclasts and the fragmentation sequence in explosive volcanic eruptions. J Geophys Res: Oceans 103:29759-29779. https://doi.org/10.1029/98JB02795

Kelfoun K (2017) A two-layer depth-averaged model for both the dilute and the concentrated parts of pyroclastic currents. J Geophys Res, SE 122:4293-4311. https://doi.org/10.1002/2017JB014013

Kelfoun K, Samaniego P, Palacios P, Barba D (2009) Testing the suitability of frictional behaviour for pyroclastic flow simulation by comparison with a well-constrained eruption at Tungurahua volcano (Ecuador). Bull Volcanol 71:1057-1075. https://doi.org/10.1007/ s00445-009-0286-6

Komorowski J-C, Boudon G, Semet M, Villemant B, Hammouya G (2002) Recurrent flank-collapses at Soufriére of Guadeloupe Volcano: implications of acid hydrothermal fluids on edifice stability Mount Pelée 1902-2002; explosive volcanism in subduction zones, IPGP-INSU-IAVCEI International Congress. Ile de la Martinique 12-16:69

Komorowski J-C, Boudon G, Semet M, Beauducel F, Anténor-Habazac C, Bazin S, Hammmouya G (2005) Volcanic Hazard Atlas of the Lesser Antilles: Guadeloupe. In: Lindsay J, Robertson R, Shepherd J, Ali S (eds) Volcanic Hazard Atlas of the Lesser Antilles, published by University of the West Indies. Seismic Research Unit, Trinidad and IAVCEI, pp 65-102

Komorowski J-C, Legendre Y, Caron B, Boudon G (2008) Reconstruction and analysis of sub-plinian tephra dispersal during the 1530 A.D. Soufrière (Guadeloupe) eruption: Implications for scenario definition and hazards assessment. J Volcanol Geotherm Res 178:491-515. https://doi.org/10.1016/j.jvolgeores.2007.11.022

Komorowski J-C, Legendre Y, Boudon G et al (2012) A new Holocene eruptive chronology for La Soufrière of Guadeloupe volcano: implications for credible scenario definition as well as hazard and impact modelling. Cities on Volcanoes 7, 18-23 November 2012, IAVCEI, Colima, Mexico

Komorowski, J-C, Legendre Y, Barsotti S (2013) Assessing long term hazards for La Soufrière of Guadeloupe volcano: insights from a new eruptive chronology, credible scenario definition, and integrated impact modelling. International Association of Volcanology and Chemistry of the Earth's Interior (IAVCEI), Scientific Assembly, Kagoshima, Japan, 19-24 July 2013, abstract, 4W 4D-P1

Komorowski J-C, Jenkins S, Baxter PJ et al (2015) Paroxysmal dome explosion during the Merapi 2010 eruption: processes and facies relationships of associated high-energy pyroclastic density currents. J Volcanol Geotherm Res:1-35. https://doi.org/10.1016/j. jvolgeores.2013.01.007

Koyaguchi T, Suzuki YJ (2018) The condition of eruption column collapse: 1. A reference model based on analytical solutions. J Geophys Res, SE 123:7461-7482. https://doi.org/10.1029/2017JB015308

La Spina G, Polacci M, Burton M, de' Michieli Vitturi M (2017) Numerical investigation of permeability models for low viscosity magmas: application to the 2007 Stromboli effusive eruption. Earth Planet Sci Lett 473:279-290. https://doi.org/10.1016/j.epsl. 2017.06.013

Legendre Y (2012) Reconstruction fine de l'histoire éruptive et scenarii éruptifs à La Soufrière de Guadeloupe: vers un modèle intégré de fonctionnement du volcan. $\mathrm{PhD}$ thesis, Institut de physique du globe de Paris, Université Paris Diderot, 1-430 pp, annexes 1-257 pp

Leone F, Komorowski J-C, Gherardi-Leone M, Lalubie G (2019) Integrating spatial accessibility in the design of volcano evacuation plans in the French West Indies (Guadeloupe and Martinique). 1-22. doi: https://doi.org/10.1186/s13617-019-0089-1

Loughlin SC, Calder ES, Clarke A, Cole PD, Luckett R, Mangan MT, Pyle DM, Sparks RSJ, Voight B, Watts RB (2002) Pyroclastic flows and surges generated by the 25 June 1997 dome collapse, Soufriere Hills Volcano, Montserrat. In: Druitt TH, Kokelaar BP (eds), The eruption of Soufrière Hills volcano, Montserrat, from 1995 to 1999. Geol Soc Lond Mem 21:191-209. https://doi.org/10.1144/gsl.mem. 2002.021.01.09

Lube G, Breard ECP, Esposti Ongaro T et al (2020) Multiphase flow behaviour and hazard prediction of pyroclastic density currents. Nat Rev Earth Environ 1:1-18. https://doi.org/10.1038/s43017020-0064-8

Marti J, Folch A, Neri A, Macedonio G (2000) Pressure evolution during explosive caldera-forming eruptions. Earth Planet Sci Lett 175:275287. https://doi.org/10.1016/S0012-821X(99)00296-4 
Marti A, Folch A, Costa A, Engwell S (2016) Reconstructing the plinian and co-ignimbrite sources of large volcanic eruptions: a novel approach for the Campanian Ignimbrite. Sci Rep 6:21220

Mastin LG, Guffanti M, Servranckx R, Webley P, Barsotti S, Dean K, Durant A, Ewert JW, Neri A, Rose WI, Schneider D, Siebert L, Stunder B, Swanson G, Tupper A, Volentik A, Waythomas CF (2009) A multidisciplinary effort to assign realistic source parameters to models of volcanic ash-cloud transport and dispersion during eruptions. J Volcanol Geotherm Res 186:1-12. https://doi.org/10. 1016/j.jvolgeores.2009.01.008

Miller A, Gidaspow D (1992) Dense, vertical gas-solid flow in a pipe. AICHE J 38(11):1801-1815

Moran SC, Newhall C, Roman DC (2011) Failed magmatic eruptions: late-stage cessation of magma ascent. Bull Volcanol 73:115-122. https://doi.org/10.1007/s00445-010-0444-x

Moretti R, Komorowski J-C, Ucciani G, Moune S, Jessop D, de Chabalier JB, Beauducel F, Bonifacie M, Burtin A, Vallée M, Deroussi S, Robert V, Gibert D, Didier T, Kitou T, Feuillet N, Allard P, Tamburello G, Shreve T, Saurel JM, Lemarchand A, Rosas-Carbajal M, Agrinier P, le Friant A, Chaussidon M (2020) The 2018 unrest phase at La Soufrière of Guadeloupe (French West Indies) andesitic volcano: scrutiny of a failed but prodromal phreatic eruption. J Volcanol Geotherm Res 393:106769. https://doi.org/10. 1016/j.jvolgeores.2020.106769

Neri A, Dobran F (1994) Influence of eruption parameters on the thermofluid dynamics of collapsing volcanic columns. J Geophys Res, SE 99:11833-11857. https://doi.org/10.1029/94JB00471

Neri A, Esposti Ongaro T, Macedonio G, Gidaspow S (2003) Multiparticle simulation of collapsing volcanic columns and pyroclastic flow. J Geophys Res 108:2202-2224. https://doi.org/10. 1029/2001JB000508

Neri A, Esposti Ongaro T, Menconi G, de'Michieli Vitturi M, Cavazzoni C, Erbacci G, Baxter PJ (2007) 4D simulation of explosive eruption dynamics at Vesuvius. Geophys Res Lett 34:L04309-L04307. https://doi.org/10.1029/2006GL028597

Neri A, Bevilacqua A, Esposti Ongaro T, Isaia R, Aspinall WP, Bisson M, Flandoli F, Baxter PJ, Bertagnini A, Iannuzzi E, Orsucci S, Pistolesi M, Rosi M, Vitale S (2015a) Quantifying volcanic hazard at Campi Flegrei caldera (Italy) with uncertainty assessment: 2. Pyroclastic density current invasion maps. J Geophys Res, SE 120:2330-2349. https://doi.org/10.1002/2014JB011776

Neri A, Esposti Ongaro T, Voight B, Widiwijayanti C (2015b) Pyroclastic density current hazards and risk. In: Shroder JF JF, Papale P (eds) Volcanic hazards, risks and disasters. Elsevier, Amsterdam, pp 109-140

Newhall CG, Self S (1982) The volcanic explosivity index (VEI) an estimate of explosive magnitude for historical volcanism. J Geophys Res 87:1231-1238. https://doi.org/10.1029/ JC087iC02p01231

Ogburn SE, Calder ES (2017) The relative effectiveness of empirical and physical models for simulating the dense undercurrent of pyroclastic flows under different emplacement conditions. Front Earth Sci 5: 63-26. https://doi.org/10.3389/feart.2017.00083

Ogburn SE, Calder ES, Cole PD, Stinton AJ (2014) Chapter 10 The effect of topography on ash-cloud surge generation and propagation. Geol Soc Lon, Memoirs 39:179-194. https://doi.org/10.1144/M39.10

Oreskes N, Shrader-Frechette K, Belitz K (1994) Verification, validation, and confirmation of numerical models in the earth sciences. Science 263:641-646. https://doi.org/10.1126/science.263.5147.641

OVSG-IPGP (1999-2020) Monthly report on the volcanic activity of La Soufrière de Guadeloupe and on the regional seismicity", Observatoire Volcanologique et Sismologique de la Guadeloupe, Institut de physique du globe de Paris, IPGP-CNRS-INSU, Conseil Général de Guadeloupe. Published online at: http: //www. ipgp.fr/fr/ovsg/bulletins-mensuels-de-lovsg; ISSN 1622-4523.
Paris R (2015) Source mechanisms of volcanic tsunamis. Philos Trans R Soc A Math Phys Eng Sci 373:20140380-20140315. https://doi. org/10.1098/rsta.2014.0380

Patra AK, Bauer AC, Nichita CC, Pitman EB, Sheridan MF, Bursik M, Rupp B, Webber A, Stinton AJ, Namikawa LM, Renschler CS (2005) Parallel adaptive numerical simulation of dry avalanches over natural terrain. J Volcanol Geotherm Res 139:1-21. https:// doi.org/10.1016/j.jvolgeores.2004.06.014

Peruzzetto M, Komorowski J-C, Le Friant A et al (2019) Modeling of partial dome collapse of La Soufrière of Guadeloupe volcano: implications for hazard assessment and monitoring. Sci Rep Nature Publishing Group 9:1-15. https://doi.org/10.1038/s41598-01949507-0

Pichavant M, Poussineau S, Lesne P, Solaro C, Bourdier J-L (2018) Experimental parametrization of magma mixing: application to the CE 1530 eruption of La Soufrière de Guadeloupe (Lesser Antilles). J Petrol 59(2):257-282

Pitman EB, Le L (2005) A two-fluid model for avalanche and debris flows. Phil Trans Royal Soc A: Math Phys Eng Sci 363:15731601. https://doi.org/10.1098/rsta.2005.1596

Préfet de la Région Guadeloupe (2019) Arrêté N. 971-2019-01-14-006 du 14 janvier 2019 relatif à l'arrêté instituant un accès réglementé au sommet du volcan de la Soufrière (in French). http://www. guadeloupe.gouv.fr/content/download/15905/103671/file/Arr\% C3\%AAt\%C3\%A9\%20du\%2014\%20janvier\%202019\% 20instituant $\% 20$ un $\% 20$ acc $\%$ C3\%A8s\%20r\%C3\%A9glement $\%$ C3\%A9\%20au\%20sommet $\% 20$ du $\% 20$ volcan $\% 20$ de $\% 201 \mathrm{a} \%$ 20Soufri\%C3\%A8re.pdf

Procter JN, Cronin SJ, Platz T, Patra A, Dalbey K, Sheridan M, Neall V (2010) Mapping block-and-ash flow hazards based on Titan 2D simulations: a case study from Mt. Taranaki, NZ. Nat Hazards 53: 483-501. https://doi.org/10.1007/s11069-009-9440-x

Pudasaini SP, Mergili M (2019) A multi-phase mass flow model. J Geophys Res Earth Surf 124:2920-2942. https://doi.org/10.1029/ 2019JF005204

Pyle DM (1989) The thickness, volume and grainsize of tephra fall deposits. Bull Volcanol 51:1-15. https://doi.org/10.1007/bf01086757

Roche O, Attali M, Mangeney A, Lucas A (2011) On the run-out distance of geophysical gravitational flows: Insight from fluidized granular collapse experiments. Earth Planet Sci Lett 311:375-385. https:// doi.org/10.1016/j.eps1.2011.09.023

Rosas-Carbajal M, Komorowski J-C, Nicollin F, Gibert D (2016) Volcano electrical tomography unveils edifice collapse hazard linked to hydrothermal system structure and dynamics. Sci Rep:111. https://doi.org/10.1038/srep29899

Rutarindwa R, Spiller ET, Bevilacqua A, Bursik MI, Patra AK (2019) Dynamic probabilistic hazard mapping in the Long Valley Volcanic Region CA: integrating vent opening maps and statistical surrogates of physical models of pyroclastic density currents. J Geophys Res, SE 124(9):9600-9621

Samper A, Quidelleur X, Komorowski J-C, Lahitte P, Boudon G (2009) Effusive history of the Grande Découverte Volcanic Complex, southern Basse-Terre (Guadeloupe, French West Indies) from new K-Ar Cassignol-Gillot ages. J Volcanol Geotherm Res 187:1-14. https://doi.org/10.1016/j.jvolgeores.2009.08.016

Sandri L, Tierz P, Costa A, Marzocchi W (2018) Probabilistic hazard from pyroclastic density currents in the Neapolitan area (Southern Italy). J Geophys Res, SE 123:3474-3500. https://doi.org/10.1002/ 2017JB014890

Scott WE, Hoblitt RP, Torres RC, Self S, Martinez MML, Nillos T (1996) Pyroclastic flows of the June 15, 1991, climactic eruption of Mount Pinatubo. In: Newhall CG, Punongbayan R (eds) Fire and Mud: eruptions and lahars of Mount Pinatubo, Philippines. Philippine Institute of Volcanology and Seismology, Quezon City. University of Washington Press, Seattle, pp 545-570 
Sheridan MF, Malin MC (1983) Application of computer-assisted mapping to volcanic hazard evaluation of surge eruptions: Vulcano, Lipari, and Vesuvius. J Volcanol Geotherm Res 17:187-202. https://doi.org/10.1016/0377-0273(83)90067-7

Shimizu HA, Koyaguchi T, Suzuki YJ (2017) A numerical shallow-water model for gravity currents for a wide range of density differences. Progr Earth Planet Sci 4. https://doi.org/10.1186/s40645-017-01202

Shimizu HA, Koyaguchi T, Suzuki YJ (2019) The run-out distance of large-scale pyroclastic density currents: a two-layer depth-averaged model. J Volcanol Geotherm Res 381:1-17. https://doi.org/10.1016/ j.jvolgeores.2019.03.013

Smith WHF, Sandwell D (1997) Global seafloor topography from satellite altimetry and ship depth soundings. Science 277:1957-1962

Sparks RSJ (1976) Grain size variations in ignimbrites and implications for the transport of pyroclastic flows. Sedimentology 23:147-188

Sparks RSJ, Walker GPL (1977) The significance of vitric-enriched airfall ashes associated with crystal-enriched ignimbrites. J Volcanol Geotherm Res 2:329-341

Sparks RSJ, Wilson L, Hulme G (1978) Theoretical modeling of the generation, movement, and emplacement of pyroclastic flows by column collapse. J Geophys Res 83(B4):1727-1739. https://doi. org/10.1029/JB083iB04p01727

Spence RJS, Baxter PJ, Zuccaro G (2004) Building vulnerability and human casualty estimation for a pyroclastic flow: a model and its application to Vesuvius. J Volcanol Geotherm Res 133:321-343. https://doi.org/10.1016/S0377-0273(03)00405-0

Sulpizio R, Dellino P, Doronzo MD, Sarocchi D (2014) Pyroclastic density currents: state of the art and perspectives. J Volcanol Geotherm Res 283:36-65. https://doi.org/10.1016/j.jvolgeores.2014.06.014

Suzuki YJ, Koyaguchi T (2012) 3-D numerical simulations of eruption column collapse: effects of vent size on pressure-balanced jet/ plumes. J Volcanol Geotherm Res 221-222:1-13. https://doi.org/ 10.1016/j.jvolgeores.2012.01.013

Suzuki YJ, Costa A, Cerminara M, Esposti Ongaro T, Herzog M, van Eaton AR, Denby LC (2016) Inter-comparison of three-dimensional models of volcanic plumes. J Volcanol Geotherm Res 326:26-42. https://doi.org/10.1016/j.jvolgeores.2016.06.011

Takarada S (2017) The volcanic hazards assessment support system for the online hazard assessment and risk mitigation of quaternary volcanoes in the world. Front Earth Sci 5:77-14. https://doi.org/10. $3389 /$ feart.2017.00102
Tierz P, Sandri L, Costa A, Zaccarelli L, di Vito MA, Sulpizio R, Marzocchi W (2016) Suitability of energy cone for probabilistic volcanic hazard assessment: validation tests at Somma-Vesuvius and Campi Flegrei (Italy). Bull Volcanol 78:1-15. https://doi.org/ 10.1007/s00445-016-1073-9

Tinti S, Pagnoni G, Piatanesi A (2003) Simulation of tsunamis induced by volcanic activity in the Gulf of Naples (Italy). Nat Hazards Earth Syst Sci 3(5):311-320. https://doi.org/10.5194/nhess-3-311-2003

Todesco M, Neri A, Esposti Ongaro T, Papale P, Rosi M (2006) Pyroclastic flow dynamics and hazard in a caldera setting: application to Phlegrean Fields (Italy). Geochem Geophys Geosyst 7. https://doi.org/10.1029/2006GC001314

Trolese M, Cerminara M, Esposti Ongaro T, Giordano G (2019) The footprint of column collapse regimes on pyroclastic flow temperatures and plume heights. Nat Commun 10:2476. https://doi.org/10. 1038/s41467-019-10337-3

Valentine GA, Sweeney MR (2018) Compressible flow phenomena at inception of lateral density currents fed by collapsing gas-particle mixtures. J Geophys Res, SE 123:1286-1302. https://doi.org/10. 1002/2017JB015129

Villemant B, Hammouya G, Michel A, Semet MP, Komorowski JC, Boudon G, Cheminée JL (2005) The memory of volcanic waters: shallow magma degassing revealed by halogen monitoring in thermal springs of La Soufrière volcano (Guadeloupe, Lesser Antilles). Earth Planet Sci Lett 237:710-728. https://doi.org/10.1016/j.epsl. 2005.05.013

Wadge G, Aspinall WP (2014) A review of volcanic hazard and riskassessment praxis at the Soufrière Hills Volcano, Montserrat from 1997 to 2011. In: Wadge G, Robertson REA, Voight B (eds) The Eruption of Soufrière Hills Volcano, Montserrat from 2000 to 2010. Geol Soc Lond Mem 39:439-456. https://doi.org/10.1144/M39.24

Wilson L, Sparks R, Walker GPL (1980) Explosive volcanic eruptionsIV. The control of magma properties and conduit geometry on eruption column behaviour. Geophys J Int 63:117-148. https://doi.org/ 10.1111/j.1365-246x.1980.tb02613.x

Woods AW (1988) The fluid dynamics and thermodynamics of eruption columns. Bull Volcanol 50:169-193

Yamamoto T, Takarada S, Suto S (1993) Pyroclastic flows from the 1991 eruption of Unzen volcano, Japan. Bull Volcanol 55:166-175. https://doi.org/10.1007/bf00301514 